\title{
Endoplasmic reticulum stress and inflammation in the central nervous system
}

\author{
Neil T. Sprenkle ${ }^{1}$, Savannah G. Sims ${ }^{1}$, Cristina L. Sánchez ${ }^{1}$ and Gordon P. Meares ${ }^{1,2^{*}}$
}

\begin{abstract}
Persistent endoplasmic reticulum (ER) stress is thought to drive the pathology of many chronic disorders due to its potential to elicit aberrant inflammatory signaling and facilitate cell death. In neurodegenerative diseases, the accumulation of misfolded proteins and concomitant induction of ER stress in neurons contributes to neuronal dysfunction. In addition, ER stress responses induced in the surrounding neuroglia may promote disease progression by coordinating damaging inflammatory responses, which help fuel a neurotoxic milieu. Nevertheless, there still remains a gap in knowledge regarding the cell-specific mechanisms by which ER stress mediates neuroinflammation. In this review, we will discuss recently uncovered inflammatory pathways linked to the ER stress response. Moreover, we will summarize the present literature delineating how ER stress is generated in Alzheimer's disease, Parkinson's disease, Amyotrophic Lateral Sclerosis, and Multiple Sclerosis, and highlight how ER stress and neuroinflammation intersect mechanistically within the central nervous system. The mechanisms by which stress-induced inflammation contributes to the pathogenesis and progression of neurodegenerative diseases remain poorly understood. Further examination of this interplay could present unappreciated insights into the development of neurodegenerative diseases, and reveal new therapeutic targets.
\end{abstract}

Keywords: Endoplasmic reticulum stress, Unfolded protein response, Neuroinflammation, Neurodegeneration

\section{Background}

Innate immune activation has emerged as a prominent component in the pathology of many neurodegenerative diseases. Previously, the involvement of immunity in the pathogenesis of neurological disorders had been greatly underappreciated. However, within the last couple decades we have come to realize that an aberrant inflammatory program within the central nervous system (CNS) contributes to neuronal dysfunction [1]. While inflammation is considered a beneficial physiological response, as it promotes debris clearance and aids in tissue repair, sustained inflammatory signaling overwhelms the resolution capabilities of the CNS [2]. This, in turn, is thought to be fundamental to the development of harmful neuroinflammation. Brain-resident microglia and astrocytes are the main source of inflammation in the brain, and under pathological conditions these

\footnotetext{
* Correspondence: gpmeares@hsc.wvu.edu

'Department of Microbiology, Immunology and Cell Biology, West Virginia University School of Medicine, One Medical Center Drive, BMRC, Morgantown, WV 311, USA

${ }^{2}$ Blanchette Rockefeller Neurosciences Institute, West Virginia University School of Medicine, Morgantown, WV, USA
}

dysregulated glial cells facilitate the events that promote a neurotoxic microenvironment $[3,4]$. Considering that neurons have a limited regenerative capacity, excessive neuronal loss in the CNS has dire consequences on motor and cognitive function. A wealth of data now supports the hypothesis that inflammation in the CNS may contribute to neurodegeneration by establishing a feedforward inflammatory loop which ultimately leads to sustained neuronal damage $[1,2,5,6]$. Importantly, this likely reflects impairment of the normal mechanisms involved in immune responses in the brain as inflammation, glial activation and even peripheral immune infiltration are essential elements of normal tissue homeostasis and repair $[7,8]$.

One of the pathological hallmarks of many neurodegenerative diseases is the accumulation of misfolded proteins within the ER of neurons and neuroglia. In response to ER stress, cells induce a highly conserved cellular stress response called the unfolded protein response (UPR) in an attempt to maintain homeostasis [9]. The UPR program orchestrates transcriptional and translational changes in the cell to minimize stress, while 
concomitantly inducing protein quality control mechanisms in an attempt to reduce protein misfolding. If resolution fails, the temporally-regulated induction of UPR-dependent inflammatory and apoptotic pathways has the potential to exacerbate neuroinflammation and compromise cell fidelity [10-13].

Accumulating evidence suggests that cells under severe ER stress caused by various insults interfere with the immunosuppressive environment of the CNS [10, 11, 14]. These findings imply a heterogeneous cause linking ER stress in neurons, microglia and astrocytes with inflammation in the progression of neurodegeneration. Novel intracellular processes involved in this integrative cellular response continue to emerge. Here, we will introduce recently discovered signaling pathways associated with the UPR and present current findings regarding how chronic ER stress engenders neurological abnormalities. Furthermore, we will discuss how a UPR-induced inflammatory phenotype in CNS-resident cells could promote conditions responsible for impairing neuronal function.

\section{The physiological role of the UPR}

The majority of proteins destined for the secretory pathway present a hydrophobic $\mathrm{N}$-terminal signal sequence during the initial stages of translation $[15,16]$. This amino acid sequence is recognized by the cytosolic protein signal-recognition particle, which coordinates cotranslational translocation of the nascent polypeptide across the ER membrane and into the ER lumen $[17,18]$. Here, the unique environment of the ER lumen facilitates the proper folding events that create a stable protein with functional capabilities.

The ER serves as the cell's largest calcium store owing to the consistent active transport of calcium into the lumen [19]. Intraluminal ER calcium is necessary for the activation of calcium-dependent molecular chaperones, including the ER resident glucose-regulated proteins (GRPs), which go on to stabilize protein folding intermediates [20]. Furthermore, the ER lumen possesses an oxidative environment which allow protein disulphide isomerases (PDIs) to catalyze the formation of disulfide bonds. Reduced PDIs are reoxidized by endoplasmic reticulum oxidoreductase $\alpha(E r o 1 \alpha)$ to allow for continuous oxidation of free cysteine residues residing on unfolded proteins [21]. Additional post-translational modifications, such as glycosylation, are executed within the ER to produce a mature protein that is packaged into coat protein complex II-coated vesicles and exported out of the ER [22, 23]. ER-derived vesicles then enter the canonical secretory pathway where cargo is either targeted to the plasma membrane or to other cellular compartments.

Features of pathophysiological stress in the form of gene mutations, protein aggregates, inflammatory signals, metabolic alterations, pathogen-associated molecular patterns (PAMPs), danger-associated molecular pattern molecules (DAMPs) and/or reactive oxygen or nitrogen species (ROS/RNS) disrupts efficient protein folding processes in the ER lumen, thus creating an imbalance between the protein load and the folding capabilities of the ER [24]. The UPR responds to cellular stress by triggering effector mechanisms that can be grouped as adaptive, alarming or pro-apoptotic [20]. In the adaptive phase of the UPR, mammalian cells are able to tolerate moderate protein misfolding by upregulating the expression of chaperone proteins to correctly fold and stabilize the increasing amount of polypeptide transported into the ER lumen. In an effort to maintain quality control, the cell also employs ER-associated degradation (ERAD) and attenuates translation of global messenger RNA (mRNA) to alleviate the protein load within the lumen $[25,26]$. In more severe situations, the protein folding capacity of the ER fails to keep pace with the increasing influx of polypeptide, as the extensive accumulation of misfolded proteins in the ER lumen begins to overwhelm the compensatory mechanisms of the UPR. If improperly regulated, the buildup of misfolded proteins will compromise normal cellular processes. Under these conditions, the cell initiates signaling pathways associated with cellular stress, most notably the activation of inflammatory pathways, and 'alarms' the extracellular environment of the distress so that the appropriate tissue-wide response is initiated [20]. If all else fails the UPR will trigger cell death through both caspase-dependent and -independent means [27-29].

\section{Signal transducers of the ER stress response}

In mammalian cells, the central proteins involved in initiating this evolutionarily conserved response are activating transcription factor 6 (ATF6), inositol-requiring $1 \alpha$ (IRE-1 $\alpha$ ) and double-stranded RNA dependent protein kinase-like ER kinase (PERK) [24]. GRP78 (also known as binding immunoglobulin protein (BiP)) primarily regulates the initiation of the UPR through its direct interactions with each signal transducing sensor [30-32] (Fig. 1). Physical contact between GRP78 and the luminal domain of the ER-transmembrane proteins stabilizes their inactive state. High demand for chaperonemediated protein stabilization brought on by increases in protein synthesis or defective protein folding recruits GRP78 away from these proteins [31]. Disrupting this interaction frees the luminal domain of the ER sensors, consequently inducing their functional conformation. Recent evidence has suggested an additional regulatory mechanism by which the sensors become catalytically active. By crystallizing the yeast IRE-1, Credle et al. elucidated a distinct peptide-binding groove in the IRE-1 luminal domain $[33,34]$. In this model, unfolded 


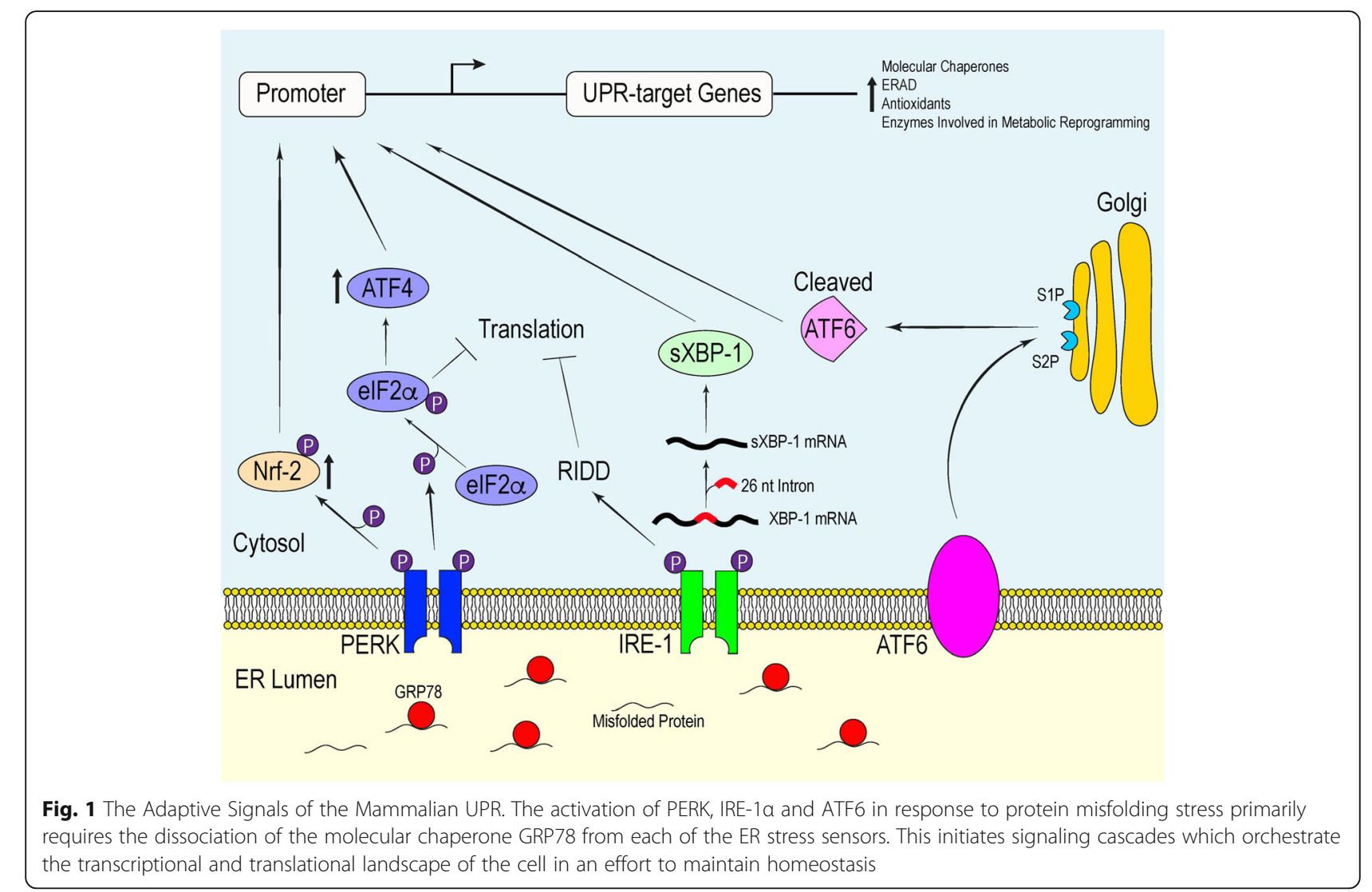

polypeptide within the ER lumen may act as a substrate for the peptide-binding groove located in IRE-1. Because of the shared structural homology with that of IRE-1, PERK may also be activated in a similar manner [33]. These findings represent a unique sensing mechanism that regulates the activation of the UPR.

Interplay between active ATF6, IRE- $1 \alpha$ and PERK initiate signaling cascades that regulate the transcriptional and translational landscape of the cell to selectively promote the expression UPR-target genes. Each of these mediators promote distinct signaling pathways which converge to produce an effective response to mitigate damage. If overwhelmed, these signaling proteins will initiate apoptosis [35] (Fig. 2).

Mammalian ATF6 is a type II transmembrane protein embedded within the ER membrane [36]. The carboxyl terminus of ATF6 acts as the intraluminal sensor while the amino terminus protrudes into the cytosol and functions as a basic leucine zipper (bZIP) transcription factor [37]. Dissociation of GRP78 from the luminal domain causes ATF6 to translocate to the Golgi apparatus. Located at the Golgi are site- 1 and site- 2 proteases, both of which have been implicated in the regulation of cholesterol metabolism [38]. It is here that ATF6 is cleaved, resulting in the release of the bZIP transcription factor into the cytosol [36]. From the cytosol, the processed
ATF6 fragment localizes into the nucleus and helps upregulate the expression of genes responsible for mediating protein folding and ERAD [36, 39].

IRE- $1 \alpha$ is a type 1 transmembrane protein containing an ER-sensing amino terminus, and a cytosolic carboxyl terminal endoribonuclease (RNase) and serine-threonine kinase domain [31, 40, 41]. Detection of unfolded proteins causes IRE- $1 \alpha$ to dimerize and/or form higher order oligomers, which in turn activates its kinase domain. Subsequent trans and autophosphorylation stimulates the RNase activity of IRE-1 $\alpha$ [42]. Acquisition of RNase catalytic activity enables for the excision of a 26nucleotide intron within a mature X-box-binding protein 1 (XBP1) mRNA transcript in the cytosol [43]. The spliced XBP1 (sXBP1) mRNA encodes for an XBP1 isoform which, like ATF6, binds upstream cis-elements associated with chaperone and ERAD-mediated genes $[39,44]$. Sustained ER stress augments the RNase activity of IRE-1 $\alpha$, thereby causing decreased specificity for XBP1 mRNA and elevated degradation of specific classes of mRNAs, $28 \mathrm{~S}$ ribosomal RNA and microRNAs through regulated IRE1-dependent decay (RIDD) [45]. The degradation of RNA transcripts destined for the ER and ribosomal RNA is thought to initially help diminish mRNA translation to alleviate the protein load on the ER [46]. Nevertheless, prolonged RIDD activity resulting 


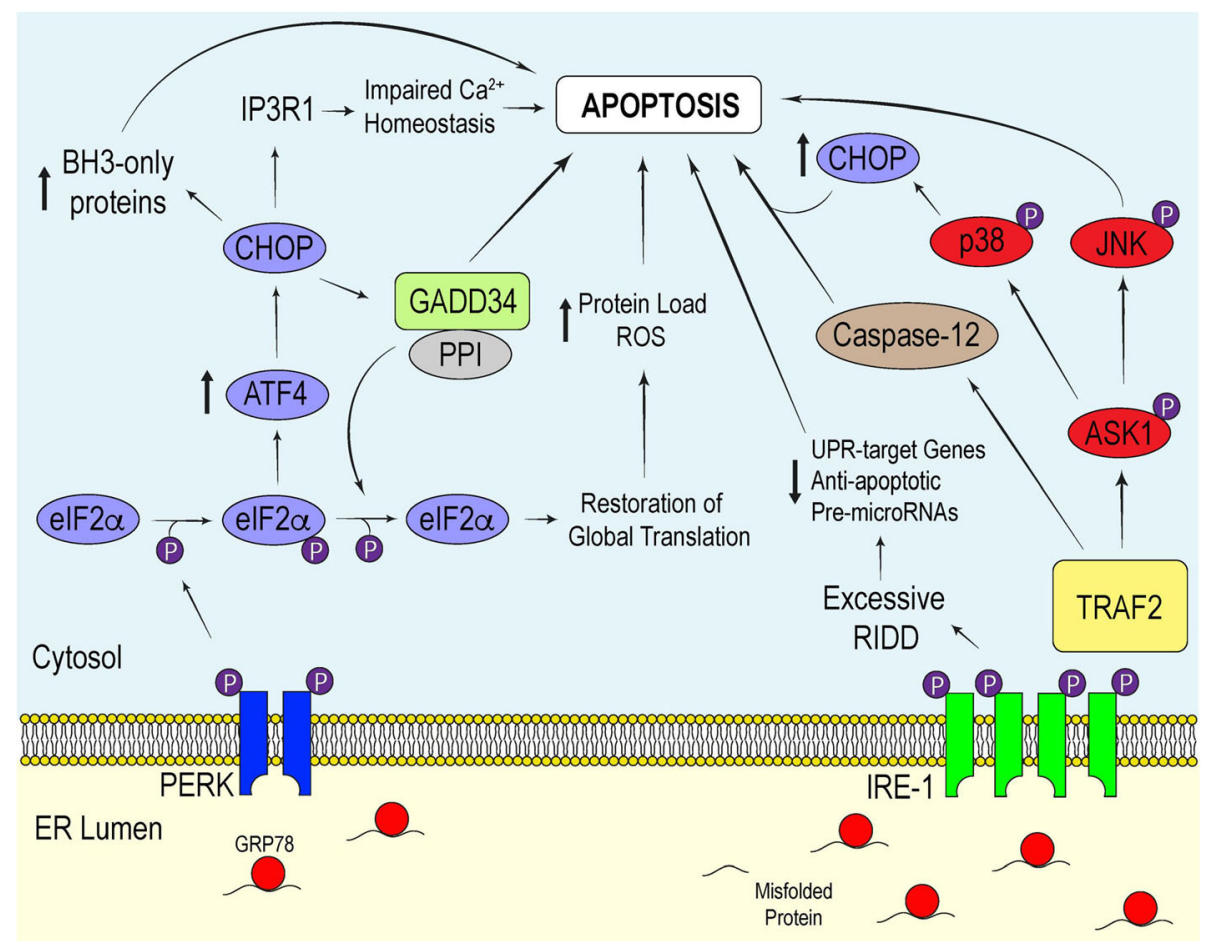

Fig. 2 Apoptotic Signals Associated with Chronic UPR Activation. Persistent ER stress triggers the apoptotic component of the UPR. PERK and IRE-1 a drive UPR-induced apoptosis by initiating pathways which facilitate enhanced ROS production, $\mathrm{Ca}^{2+}$ dysregulation and caspase activation

from chronic ER stress contributes to cell death by degrading ER-targeted mRNA that encode proteins involved in protein folding and anti-apoptotic microRNA, thus pushing cell fate toward apoptosis [47-49].

Lastly, PERK possesses type 1 transmembrane topology and a cytosolic kinase domain [31]. Structural analysis has revealed that the sensing luminal domain of PERK shares a conserved protein sequence with that of IRE-1 $\alpha$ [26]. Unsurprisingly, both PERK and IRE-1 $\alpha$ respond to ER stress in a similar manner. Along with IRE-1 $\alpha$, PERK indirectly reduces the quantity of unfolded polypeptide within the ER to allow for more efficient chaperone-mediated protein folding in a wellsaturated ER lumen. The dimerization of PERK leads to the activation of its cytosolic kinases, which subsequently phosphorylate serine 51 on the $\alpha$-subunit of eukaryotic initiation factor $2 \alpha$ (eIF2 $\alpha$ ) [26]. Phosphorylation of eIF $2 \alpha$ prevents the translation of many nuclear-encoded mRNA transcripts by compromising the formation of the GTP.eIF2 $\alpha \cdot$ Met-tRNA $A_{i}$ ternary complex, which in turn prevents the assembly of the pre-initiation complex at the $5^{\prime}$ end of mRNA [50, 51]. Delaying translation re-initiation in this manner increases the probability that ribosomes will scan past inhibitory upstream open reading frames, resulting in increased translation of a specific subset of mRNAs, most notably mRNA that encodes ATF4 [50,52]. Like ATF6, ATF4 is a bZIP transcription factor important for maintaining intracellular homeostasis through the upregulation of UPR-target genes involved in efficient protein folding, the antioxidant response and amino acid biosynthesis and transport [53]. In addition to promoting an adaptive response, ATF4 regulates the transcription of the gene encoding pro-apoptotic factor CCAAT-enhancerbinding protein homologous protein (CHOP) [54].

While the role of $\mathrm{CHOP}$ in stress-induced apoptosis remains obscure, it is thought that $\mathrm{CHOP}$ promotes apoptosis by 1) downregulating the expression of Bcl-2, a pro-survival proto-oncogene, 2) elevating the expression of pro-apoptotic BH3-only Bcl-2 family proteins such as Bad, Bim and p53 upregulated modulator of apoptosis and 3) coordinating intracellular calcium signaling $[54,55]$. The latter relies on the involvement of the ER. In addition to its role in mediating stable protein folding, the ER serves an important function in cell signaling due to its ability to release calcium in response to second messengers. During unremitting PERK activation, $\mathrm{CHOP}$ accumulates to a point necessary to activate Erol $\alpha$, which drives the aperture of the ER calcium release channel inositol 1, 4, 5-triphosphate (IP3) receptor $1[56,57]$. Prolonged efflux of calcium from the ER promotes the activation of calcium/calmodulin-dependent protein kinase II, which plays a role in promoting cell death [57]. Moreover, free cytosolic calcium leaks into the mitochondrial matrix, causing mitochondrial 
depolarization [58]. Mitochondrial uptake of calcium released from the ER also elevates the production of ROS through various mechanisms, including activating the mitochondrial permeability transition and stimulating Krebs cycle dehydrogenases [53, 58, 59]. Besides facilitating calcium release, Ero1 $\alpha$ contributes to the production of hydrogen peroxide within the ER lumen [60].

Along with targeting Bcl-2 family genes and Ero1 $\alpha$, $\mathrm{CHOP}$ binds to promoter elements associated with growth arrest and DNA damage-inducible protein 34 (GADD34). The induction of GADD34 is imperative for attenuating signals downstream of the PERK-eIF2 $\alpha$ ATF4 pathway. This GADD34-dependent negative feedback loop relies on GADD34 recruiting protein phosphatase 1 (PP1) to dephosphorylate eIF2 $\alpha$. Mutating the conserved motifs important for binding PP1 in GADD34 impairs eIF2 $\alpha$ dephosphorylation, thus supporting its regulatory role in mediating the phosphorylation state of eIF2 $\alpha$ [61]. Moreover, knocking out CHOP diminishes GADD34 protein expression, leading to elevated levels of phosphorylated eIF $2 \alpha$ when compared to wild-type (WT) cells experiencing ER stress [62]. Although GADD34-mediated dephosphorylation of eIF2 $\alpha$ is essential for cells to restore global mRNA translation after acute insult, the overexpression of GADD34 increases the translation of mRNA transcripts induced during the later stages of prolonged ER stress, thereby elevating the protein load and restoring global translation of proteins involved in ROS production and apoptosis [63]. Additionally, GADD34 may have proapoptotic effects that are independent of its role in regulating eIF2 $\alpha$ phosphorylation that contribute to ER stress-induced cell death $[62,64]$.

Another downstream effector of active PERK is the bZIP transcription factor nuclear factor-like 2 (Nrf-2), which is important for the expression of antioxidants [65]. Nrf-2 is normally sequestered within the cytosol by kelch-like ECH-associated protein 1 (Keap1) under basal states, however, the initiation of the UPR allows PERK to act on the Nrf-2-Keap1 complex. PERK-mediated phosphorylation of Nrf-2 promotes its dissociation from Keap1 and translocation into the nucleus where it upregulates the expression of genes essential for redox homeostasis. Cullinan et al. demonstrated that deleting Nrf-2 compromises the ability of mouse embryonic fibroblasts (MEFs) to cope with ER stress, as cells without Nrf-2 were more susceptible to undergoing ER stressinduced apoptosis compared to WT MEFs treated with tunicamycin, a pharmacological ER stress-inducing agent that blocks $\mathrm{N}$-linked glycosylation [66]. The same study also provided evidence showing that PERK phosphorylation was sufficient to disrupt the Nrf-2-Keap1 complex, thereby allowing Nrf-2 to function as a transcription factor independent of the presence of ROS/RNS.
During the UPR, PERK and ATF6 signaling have been shown to upregulate the expression of sXBP1 mRNA (through different mechanisms) to produce an operative transcription factor responsible for inducing the expression of stress-response genes [67, 68]. Furthermore, there is evidence that the transcription of $\mathrm{CHOP}$ is also under the control of the active ATF6 transcription factor [69]. This demonstrates that not only do the ER sensors elicit independent signaling cascades in the face of ER stress, but there is cross-talk between the different UPR pathways in an effort to provide a robust response to physiological stress. In addition to ATF6 and IRE- $1 \alpha$ regulating the transcription of chaperone proteins and enzymes mediating ERAD, both have also been implicated in the biosynthesis of ER phospholipids, which are used to expand the ER membrane, and in the regulation of other aspects of cellular metabolism [70, 71]. Interestingly, components of the UPR play an essential role in learning, memory and behavior. The eIF $2 \alpha$ kinases, including PERK, regulate memory and synaptic plasticity by modulating gene expression and translation [72]. Moreover, a recent study demonstrated an important role for XBP1 in facilitating memory and long-term potentiation through the regulation of brain-derived neurotrophic factor expression [73]. The involvement of the UPR in optimizing the protein folding capacity of the ER as well as modulating cellular metabolism and cognitive function highlights the pleiotropic actions of the ER stress response in maintaining tissue and organismal homeostasis.

\section{UPR-mediated inflammatory pathways}

In addition to coordinating the expression of stressresponse genes during ER stress, the UPR initiates inflammatory pathways essential for the innate immune response (Fig. 3). The principal inflammatory signaling proteins activated during the UPR are the nuclear factor kappa-light-chain-enhancer of activated $\mathrm{B}$ cells (NF- $\mathrm{kB}$ ) and the mitogen activated protein kinase (MAPK) family proteins c-Jun N-terminal kinase (JNK) and p38. It is important to note that NF-kB and the MAPKs regulate not only inflammatory gene expression, but they also play a role in mediating cell survival in a context-specific manner [74].

The NF- $\mathrm{BB}$ family of proteins are made up of homoand heterodimeric transcription factors composed of proteins in the NF- $\mathrm{kB} /$ Rel family [75]. In unstressed cells, NF- $\mathrm{kB}$ is sequestered within the cytosol through physical interaction with inhibitors of $\kappa B$ (ІкB). Signaling through the canonical NF- $\mathrm{BB}$ pathway activates the serine kinase $\mathrm{I} K \mathrm{~B}_{\mathrm{K}}$ kinase (IKK), which is composed of two catalytic subunits (IKK $\alpha$ and IKK $\beta$ ) and a regulatory subunit $(\mathrm{IKK} \gamma)$. Site-specific phosphorylation of IкB by IKK signals for its degradation through the ubiquitindependent recruitment of the $26 \mathrm{~S}$ proteasome [76]. 


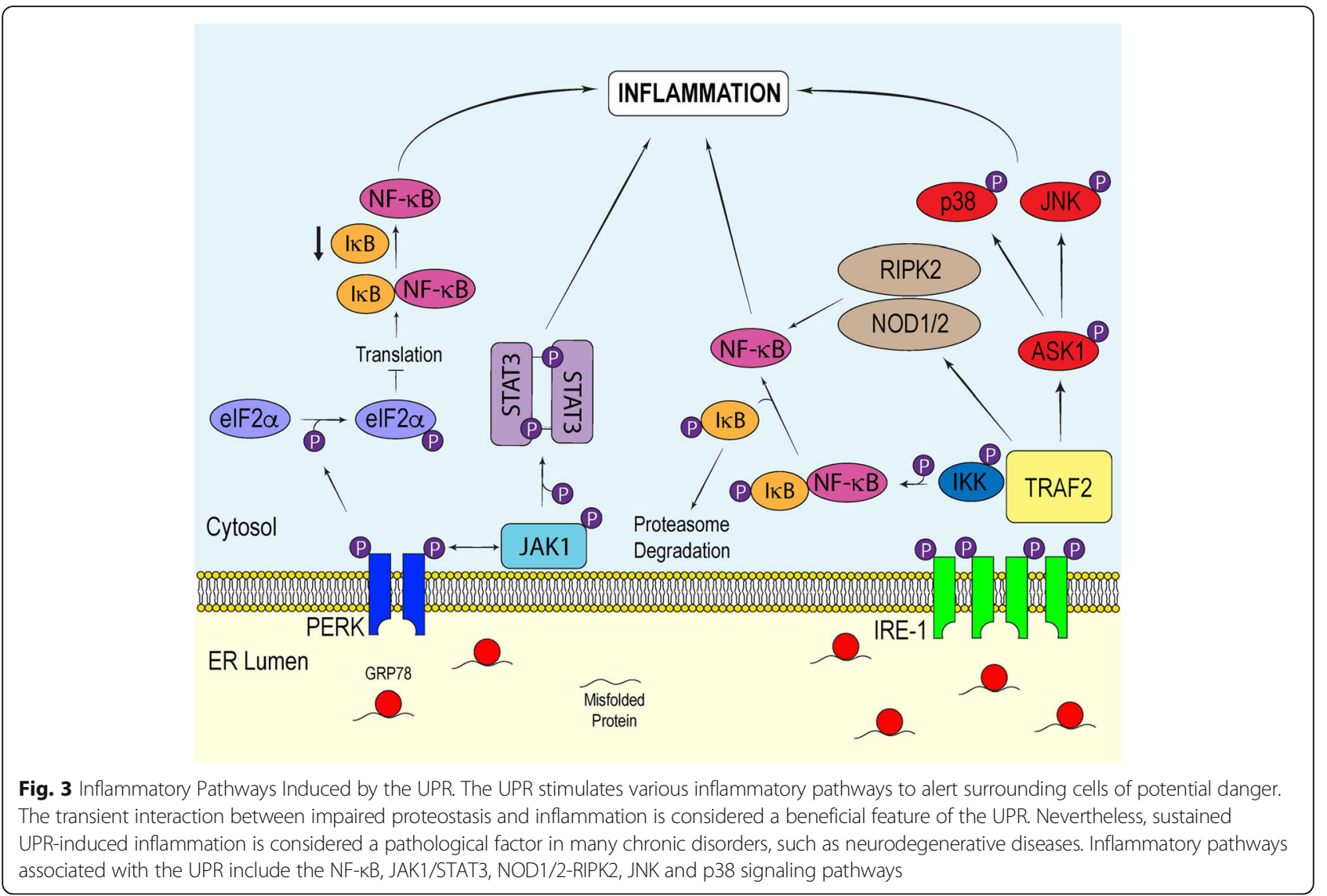

Subsequently, free NF- $\mathrm{kB}$ is able to localize to the nucleus and bind to $\mathrm{kB}$ sites in gene promoters, and drive the expression of cytokines and cell survival proteins. NF- $\mathrm{kB}$ can be activated by various forms of cell stress. For example, in addition to ER stress, elevated levels of cytosolic calcium and oxidative stress have been shown to promote NF-kB-mediated transcription [77, 78]. In the context of ER stress, the attenuation of global mRNA translation in response to eIF $2 \alpha$ phosphorylation provides a means by which NF- $\mathrm{kB}$ is stimulated. Depressing mRNA translation decreases protein levels of I $\kappa B$ and NF- $\kappa B$ within the cytosol [79]. Because I $\mathrm{KB}$ has a shorter half-life than NF- $k B$, the higher proportion of $\mathrm{NF}-\kappa \mathrm{B}$ to I $\mathrm{B}$ favors the migration of free NF- $\mathrm{kB}$ into the nucleus to upregulate the transcription of inflammatory genes.

Along with PERK, IRE-1 $\alpha$ elicits inflammatory signaling during the ER stress response. After oligomerization, IRE-1 $\alpha$ recruits the adaptor protein tumor-necrosis factor- $\alpha$ (TNF- $\alpha$ )-receptor-associated factor 2 (TRAF2), which couples the activation of IRE- $1 \alpha$ with different inflammatory pathways. The formation of the IRE- $1 \alpha-$ TRAF2 complex mediates cross-talk between active IRE$1 \alpha$ and the NF- $\kappa B$ and MAPK signaling pathways. TRAF2 directly interacts with IKK and indirectly with
JNK by activating apoptosis signal-regulating kinase 1 (ASK1), which then coordinates the activation of JNK $[20,80,81]$. IRE-1 $\alpha$-mediated activation of IKK leads to the phosphorylation of IкB to promote NF-kBdependent transcriptional regulation, while the IRE- $1 \alpha-$ dependent activation of JNK stimulates the bZIP transcription factor activator protein 1 (AP-1). Thereafter, AP-1, a heterodimer composed of a differential combination of Fos, Jun, ATF and Maf sub-family members, binds to enhancer elements which upregulate the transcription of inflammatory genes [82].

Interestingly, the IRE-1 $\alpha$-TRAF2 axis has been shown to stimulate the nucleotide-binding oligomerization domain 1 and 2 (NOD1/2)-receptor-interacting serine/threonineprotein kinase 2 (RIPK2) pathway, resulting in the activation of NF-kB [83]. This proposed mechanism was supported in an in vivo murine model of Brucella abortus infection. Brucella abortus induces ER stress by injecting host cells with the VceC virulence factor via its type IV secretion system. Here, Keestra-Gounder et al. demonstrated that the resulting ER stress-induced production of interleukin (IL)-6 in infected mice was dependent on TRAF2, NOD1/2 and RIPK2 interplay. These findings provided further evidence of dynamic interactions between innate immunity and UPR-induced inflammation. 
In conjunction with its involvement in initiating inflammation, IRE- $1 \alpha$ can facilitate cell death through its interactions with the apoptotic proteins during ER stress [84]. IRE-1 $\alpha$-dependent activation of caspase- 12 has been reported to be a dispensable contributor in the execution of ER stress-induced apoptosis in mice and rats [85-87]. Nevertheless, many human variants of caspase- 12 possess loss-of-function mutations that promote the synthesis of a truncated protein without functional activity, and thus may not be a significant contributor to ER stress-induced cell death in humans [87]. The IRE-1 $\alpha$-TRAF2-JNK pathway coordinates cell death by facilitating Bax-dependent apoptosis and inhibiting the pro-apoptotic protein $\mathrm{Bcl}-2$, while the IRE-1 $\alpha$-TRAF2-p38 branch may enhance CHOP transcriptional activity $[20,88,89]$. This understanding highlights the importance of TRAF2 in linking the UPR to a diverse range of signaling pathways to trigger the appropriate physiological response.

Recently, the interaction between PERK and Janus kinase 1 (JAK1) in the UPR was elucidated in astrocytes. It has been recognized that ER stress influences the JAK-signal transducers and activators of transcription (STAT) pathway $[90,91]$, however, the molecular mechanisms underlying its involvement in the context of neurodegeneration and how it alters the JAK-STAT pathway in glial cells remained to be clarified. We observed that JAK1-STAT3 signaling in ER stressed astrocytes was dependent on PERK [92]. Transfecting astrocytes with PERK small interfering RNA, followed by treatment with thapsigargin, a non-competitive inhibitor of the sarco/endoplasmic reticulum $\mathrm{Ca}^{2+}$ ATPase used to induce ER stress, attenuated JAK1 and STAT3 phosphorylation. Additionally, PERK knockout MEFs incubated with thapsigargin expressed significantly less phosphorylated STAT3 and STAT3-dependent inflammatory cytokines and chemokines relative to their WT counterparts. Mass spectrometry revealed that JAK1 phosphorylates PERK at tyrosine 585 and 619 in vitro. While further investigation is needed to completely unravel how STAT3 is phosphorylated by the PERK/JAK1 complex, these findings present a novel pathway implicating the UPR in driving neuroinflammation.

Each of the three ER stress sensors serves a multifunctional role in maintaining ER protein homeostasis under transient ER stress. If the cell is unable to ameliorate intrinsic protein misfolding stress, the cell will induce apoptotic pathways to avoid continuously secreting distress signals to neighboring cells. The category of stimuli or environmental conditions may be an important determinant regarding whether the cell will trigger a coordinated cell death. One must also consider that certain cell types, such as highly secretory cells, must constantly maintain an optimal ER protein folding environment, making them more susceptible to ER stress.
Chronic ER stress leads to the disproportionate activation of the ATF6, IRE-1 $\alpha$ and PERK pathways to amplify the apoptotic component of the UPR [93]. Some experimental models respond to severe ER stress by attenuating ATF6 and IRE- $1 \alpha$ signaling and augmenting PERK activation to allow apoptotic signals to dominate [93]. Because CHOP possesses a short half-life, chronic PERK activation is required to overwhelm the adaptive signals of the UPR to promote cell death [94, 95]. Similarly, sustained IRE- $1 \alpha$ signaling has the potential to initiate apoptosis in other situations. While various pharmacological approaches have provided invaluable insights into the physiologic role of the UPR, more work must be done to fully appreciate how each of the branches of the UPR respond to specific stimuli and how they integrate to mediate apoptotic events.

\section{ER stress in neurodegenerative diseases}

The activation of the UPR plays an essential role in maintaining vital biological processes within the brain during cellular stress. In fact, moderate ER stress enhances cellular protection against subsequent insult by altering the transcriptome and proteome of the cell to increase the adaptive capacity of the ER, a response called the hormetic response [9, 96-99]. However, prolonged ER stress developed in neurodegenerative diseases is believed to disrupt the protective mechanisms of the UPR, leading to the activation of inflammatory and apoptotic programs that promote neurotoxicity. In the following sections we will briefly describe the mechanisms underlying how ER stress is generated in neurodegenerative diseases, such as Alzheimer's disease (AD), Parkinson's disease (PD), Amyotrophic Lateral Sclerosis (ALS) and Multiple Sclerosis (MS), then address its potential contribution to the development of pathological neuroinflammation. In general, ER stress is a consequence of disturbances in protein-quality control machinery, ER $\mathrm{Ca}^{2+}$ dysregulation, protein-trafficking impairment or direct defects in UPR components [9].

\section{Alzheimer's disease}

$\mathrm{AD}$ is a common age-dependent neurodegenerative disease that accounts for a significant number of reported dementia cases [100]. The pathology of AD is characterized by the formation of intracellular neurofibrillary tangles (NFTs) composed of hyperphosphorylated tau and the extracellular parenchymal deposition of amyloid- $\beta$ (A $\beta)$ aggregates $[101,102]$. The cytoplasmic protein tau normally serves to stabilize microtubules which form 'tracks' that facilitate intracellular vesicle trafficking and axonal elongation and maturation. This is highlighted by the finding that knocking down tau leads to severe neurite growth defects in primary cerebellar neurons [103]. However, certain insults cause an 
imbalance between the activities of tau kinases and phosphatases that lead to the abnormal phosphorylation of tau [104]. In its hyperphosphorylated state, tau becomes soluble and, in turn, polymerizes to form oligomers and/or NFTs [105]. In the case for $A \beta$ pathology, genetic studies have implicated mutations in $\mathrm{A} \beta$ precursor protein (APP) and in the transmembrane proteins presenilin-1 (PS1) and presenilin-2 (PS2), which act as subunits for the $\gamma$-secretase complex, as the predominant genetic factors contributing to the onset of familial $\mathrm{AD}[106,107]$. Potentially pathological $\mathrm{A} \beta$ is liberated when APP is sequentially cleaved at the plasma membrane by $\beta$-secretase, then $\gamma$-secretase. [101]. This leads to an extracellular accumulation of either total $A \beta$ or increase relative concentrations of amyloidogenic $A \beta$, such as $A \beta 42$. Impaired clearance of $A \beta$ has also been implicated in $\mathrm{AD}$, as it creates an imbalance of its turnover in the brain [108].

Chronic ER dysfunction is highly associated with the memory and cognitive manifestations commonly observed in different experimental models of $\operatorname{AD}[109,110]$. To this point, Ma et al. elucidated that selectively abating the expression of PERK in mice possessing AD-linked mutations in genes encoding APP and PS1 prevented the aberrant phosphorylation of eIF2 $\alpha$ [111]. This, in turn, improved synaptic plasticity and spatial memory in AD mice, consistent with the requirement for active protein translation in memory consolidation [112]. Interestingly, sXBP1 overexpression ameliorates cognitive function in the $3 \times \mathrm{Tg} \mathrm{AD}$ mouse model [113]. The eIF2 $\alpha$ kinases general control non-derepressible 2 (GCN2) [111] and double stranded RNA-dependent kinase (PKR) have also been implicated in memory impairment $[110,114]$. Multiple studies have demonstrated that $A \beta$ oligomers can activate PKR and induce ER stress by eliciting the TNF- $\alpha$ pathway $[110,115]$. Additionally, $\mathrm{A} \beta$ may stimulate ER $\mathrm{Ca}^{2+}$ release through ryanodine receptors and IP3 receptors, which triggers ER stress, neuronal apoptosis and mitochondrial fragmentation [116-118]. Inhibition of both GCN2 and PKR through different mechanisms significantly improves cognitive function in murine AD models [111, 114]. These findings suggest that pathophysiological conditions, not just ER stress, which lead to sustained eIF2 $\alpha$ phosphorylation have the potential to aggravate the cognitive abnormalities seen in AD.

Abnormal protein aggregates interfere with the normal processes involved in protein maintenance and trafficking in models of neurodegeneration. Regarding AD, soluble tau has been shown to cause pathological ER stress by targeting and impairing components involved in ERAD [119]. Paradoxically, pre-existing ER stress also promotes NFT formation. It is well known that $A \beta$ oligomer-dependent ER stress responses can lead to the activation of different kinases, such as the serine/ threonine kinase glycogen synthase kinase 3 (GSK-3) $[120,121]$. This kinase (among others) is capable of subsequently phosphorylating specific epitopes on tau that contribute to the development of NFT $[120,121]$. Therefore, ER stress and hyperphosphorylated tau could be induced by each other in a cycle to propagate $A D$ pathology [122]. More recently, however, the correlation between NFT formation and AD severity had been scrutinized [123]. It seems now that soluble oligomers of tau and $A \beta$ may be the primary neurotoxic agents that contribute to $\mathrm{AD}$ [123].

It has been suggested that familial AD-linked PS1 mutations suppress the activation of IRE- $1 \alpha$. This predisposes cells to become more susceptible to ER stress due, in part, to decreases in protein chaperone synthesis as a result of reduced UPR induction [124]. A study using SK$\mathrm{N}-\mathrm{SH}$ cells and fibroblasts expressing a PS1 mutant associated with familial AD demonstrated that mutant PS1 also disrupts PERK activation, potentially in a similar manner as IRE-1 $\alpha$, and delays nuclear accumulation of processed ATF6 in response to ER stress [125]. The aberrantly spliced isoform of PS2 (PS2V) is also linked to AD. Similar to the PS1 mutations, this isoform increases the vulnerability of the cell to ER stress [126]. Alternatively, the over-expression of PS1 and PS2 mutants in cells perturbs ER calcium homeostasis, implying another mechanism by which genetic mutations in the presenilin genes contribute to AD [127-129]. With this in mind, there is contradictory evidence indicating that neither ablation of PS1 or expression of familial AD-linked PS1 variants impairs the expression of GRP78 mRNA and the activation of IRE1- $\alpha$ [130]. Because of limited knowledge regarding how ER stress is generated during $\mathrm{AD}$, more investigation is needed to fully appreciate how dysregulated UPR signaling contributes to the pathology of $\mathrm{AD}$.

\section{Parkinson's disease}

PD is a chronic and progressive movement disorder characterized by the selective loss of dopaminergic neurons in the substantia nigra, and the presence of intraneuronal filamentous inclusion bodies called Lewy bodies. While the development of Lewy bodies is not a definitive causative factor, they are deemed to be a pathological hallmark of PD. A post-mortem study showed that the percentage of Lewy body-containing dopaminergic neurons positive for caspase-3 is significantly higher than the percentage of caspase-3-positive dopaminergic neurons without Lewy bodies, indicating that Lewy body-containing dopaminergic neurons are predisposed to undergo apoptosis [131]. A principal component of Lewy bodies in PD are the abnormal filaments of $\alpha$-synuclein, which seem to form due to different genetic factors, such as the multiplication of the SCNA locus, or non-genetic factors, such as aberrant post-translational modifications [132-134]. 
Common mutations implicated in autosomal recessive PD reside within the Parkin gene, which encodes for an E3 ubiquitin ligase that is necessary for mitophagy $[135,136]$. Studies using post-mortem brain samples and mouse models also suggest that Parkin can be inactivated by posttranslational modifications, such as oxidation, nitrosylation and the addition of dopamine [135]. Disrupting the E3 ligase activity of Parkin or defects in PTEN-induced kinase 1, which recruits Parkin to the outer membrane of damaged mitochondria, is thought to play a critical role in the development of familial and sporadic PD, mainly through its failure to maintain mitochondrial fidelity [137]. Similarly, mutations within the gene that encodes leucine-rich repeat kinase 2 (LRRK2) have been shown to promote PD [138]. LRRK2 is a widely expressed protein important for regulating various biological processes. Mutant LRRK2 is highly associated with the onset of inherited and sporadic PD, and the resulting LRRK2-mediated toxicity may be dependent on its kinase activity [139]. Nevertheless, the mechanisms underlying its role in the pathogenesis of PD are still being unraveled.

The notion that prolonged ER stress contributes to PD pathology was first supported with the findings that neurons in toxin-induced models of PD highly expressed genes involved in the UPR [140]. It is now appreciated that $\alpha$-synuclein-induced neurotoxicity may result from nitrosative stress, accumulation of ERAD substrates and/ or defective vesicular trafficking, all of which can lead to ER stress [141]. To this point, under conditions of nitrosative stress, S-nitrosylation directly inactivates PDI [142]. This inactivation impairs proper protein folding and hinders PDI-mediated attenuation of neuronal cell death [142]. Moreover, the concomitant accumulation of toxic $\alpha$-synuclein oligomers in the ER further exacerbates the severity of ER stress, leading to deleterious UPR signaling $[134,143]$. Some findings indicate that $\alpha$ synuclein-dependent ER stress is the result of blocking ER to Golgi vesicular trafficking, as preventing vesicle mobilization from the ER causes the accumulation of protein cargo within the ER lumen [144]. Targeting pathways associated with these abnormal phenotypes through pharmacological intervention in vitro has been shown to rescue neuronal loss observed in PD models [141].

Post-mortem analysis revealed that human PD patients exhibited greater phosphorylated PERK and eIF2 $\alpha$ in neuromelanin containing dopaminergic neurons relative to control cases [145]. In the same study, phosphorylated PERK colocalized with $\alpha$-synuclein within dopaminergic neurons derived from PD patients. PC12 cells possessing the A53T mutation in the $\alpha$-synuclein gene, a point mutation that increases the tendency of $\alpha$-synuclein to form amyloid-like fibrils, exhibit elevated levels of phosphorylated eIF2 $\alpha$, CHOP, GRP78 and active caspase-12 [146]. Treatment with the caspase inhibitor $z-V A D$ or salubrinal, which prevents the de-phosphorylation of eIF2 $\alpha$, improved cell viability of A53T PC12 cells by attenuating apoptotic signaling [146]. Taken together, these findings suggest that pathological $\alpha$-synuclein may exacerbate disease progression by promoting excessive or unmitigated ER stress responses.

Stress-induced Parkin expression serves as a protective mechanism elicited by the UPR [147, 148]. The use of chromatin immunoprecipitation led to the discovery that ATF4 regulates Parkin gene expression by binding to CREB/ATF sites in the Parkin promoter [148]. The resulting increase in Parkin protein protects against ER stress-induced cell death in neurons by preventing the toxic accumulation of Parkin substrates. Moreover, the protective function of Parkin could be partially explained with the discovery that Parkin promotes the production of sXBP-1, which upregulates the transcription of prosurvival genes [149]. Recent evidence indicates that Parkin controls the function of PS1 and PS2, suggesting a possible link between defective Parkin and the pathogenesis of both AD and PD [150]. LRRK2 also helps maintain neuronal integrity against induced Parkinsonism by alleviating the consequences of ER stress. Yuan et al. demonstrated that LRRK2 saves neuroblastoma cells and C. elegans dopaminergic neurons from 6OHDA or $\alpha$-synuclein toxicity [151]. They also demonstrated that loss of function mutations in LRRK2 compromises the expression of GRP78, resulting in the hyperactivation of p38 and elevated neuronal death. Collectively, impairment in these protective mechanisms in neurons provides an alternative disturbance that contributes to the progression of PD.

\section{Amyotrophic lateral sclerosis}

ALS is a progressive neurodegenerative disease characterized by the destruction of motor neurons, which leads to paralysis and poor patient prognosis [152]. Among cases of ALS, $10 \%$ are considered familial, while the remaining $90 \%$ of cases are sporadic [153]. A pathological hallmark of familial ALS is the formation of ubiquitinated cytoplasmic inclusions composed of misfolded superoxide dismutase-1 (SOD1) [154]. However, defects in the SOD1 gene only account for $20 \%$ of familial ALS cases, and $2 \%$ of sporadic cases [155, 156]. An accrual of evidence now connects mutations in genes encoding chromosome 9 open reading frame 72 (C9orf72), transactive response DNA binding protein 43 (TDP43), and Fused in Sarcoma RNA-binding protein (FUS) (among others) to ALS pathology [155, 157-159]. In all, a large proportion of genetic alterations implicated in ALS promote disease onset and progression by either perturbing protein quality control mechanisms, RNA integrity or cytoskeletal dynamics [155]. As in other mutations associated with neurodegenerative diseases, ALS-associated mutations are 
expressed ubiquitously within the CNS (neurons and surrounding neuroglia), with strong evidence that both cellautonomous and -nonautonomous mechanisms contribute to the progressive loss of motor neurons [155].

Mediators associated with the UPR are upregulated in the spinal cords of ALS patients and in mutant SOD1 transgenic mice [160-162]. For instance, CHOP is highly expressed in motor neurons, glial cells and spinal cords of mutant SOD1 transgenic mice [163]. A similar observation is seen in spinal cord samples of sporadic ALS patients [163]. ERAD impairment is considered a central mechanism by which mutant SOD1 induces ER stress in ALS. Here, mutant SOD1 protein has been shown to inhibit a specific component of the retro-translocation machinery involved in ERAD called Derlin-1 by directly interacting with its cytoplasmic C-terminus [164]. Failure to export misfolded substrates from the ER in NSC34 cells leads to their accumulation within the ER lumen, which promotes neuronal death by eliciting the IRE-1-TRAF2-ASK1 pathway [164].

Increased motor neuron loss and SOD1 aggregation is observed in SOD1 ${ }^{\mathrm{G} 85 \mathrm{R}}$ PERK $^{+/-}$mice compared to SOD1 ${ }^{\text {G85R }}$ mice fully expressing PERK [165]. Interestingly, ATF4 deficiency in SOD $1^{\mathrm{G} 85 \mathrm{R}}$ mice exacerbates SOD1 aggregation, but delays disease onset and reduces the expression of pro-apoptotic genes [166]. XBP1-null NSC34 motor neurons expressing mutant SOD1 are more apt to clear mutant SOD1 aggregates [167]. Moreover, silencing XBP1 in vivo provides protection against disease progression in mutant SOD1 mice [167]. Taken together, there is contradictory evidence regarding the protective effects of the UPR in experimental models of ALS, suggesting that the extent to which the UPR contributes to ALS is context-dependent.

PDI has been shown to be upregulated in SOD1 ${ }^{\text {G93A }}$ ALS rats and mice [168]. Furthermore, post-mortem human brain samples exhibit greater PDI expression in comparison to controls, implying that PDI is induced in response to the abnormalities associated with ALS [169]. The protective role of PDI in ALS emanates from its ability to facilitate folding of misfolded assemblies, thereby reducing SOD1 aggregate-mediated toxicity [169]. As seen in PD, PDI expressed in spinal cords of ALS patients is highly S-nitrosylated [170]. Increased RNS production has been reported in ALS, and the resulting nitrosative stress may impair the function of PDI through this post-translational modification [171].

Aggregates composed of mutant TDP-43, FUS or C9orf72 also initiate the UPR program [172-174]. To this point, overexpressing ALS-associated mutant TDP43 in Neuro2a neuroblastoma cells results in greater induction of CHOP, XBP1 and ATF6 [173]. Moreover, mutations in FUS contribute to the formation of cytoplasmic protein inclusions that trigger ER stress responses in NSC34 motor neurons, and are found to co-localize with PDI in post-mortem spinal cord samples from ALS patients $[175,176]$. Lastly, a study expressing poly(GA) repeats in neuronal cultures, which model ALS-associated repeat expansions in the C9orf72 gene, contribute to neuronal death by inducing ER stress [172]. When treated with salubrinal or the chemical chaperone TUDCA, these neurons are rescued from ER stress-mediated cell death, indicating that mutations in the C9orf72 gene contribute to neurotoxicity by promoting ER dysfunction [172]. Overall, these findings highlight how pathological assemblies implicated in ALS contribute to motor neuron loss. Even with the present understanding that SOD1-linked mutations only account for a relatively small proportion of ALS cases, many studies investigating the relationship between ER stress and ALS largely utilize animal models expressing mutant SOD1. Therefore, it will be of importance to further elucidate the mechanisms by which ER stress is generated in other ALS models in order to fully grasp how ER stress aggravates ALS pathology.

\section{Multiple sclerosis}

MS is T lymphocyte-mediated autoimmune disease characterized by the spatiotemporal dissemination of white matter lesions within the CNS [177]. While the etiology of MS remains in question, it is thought to be initiated by autoreactive $\mathrm{T}$ lymphocytes that have breached the blood brain barrier $(\mathrm{BBB})$ or the blood-cerebral spinal fluidbarrier and have mounted an autoimmune response directed toward self-CNS antigens [178]. Autoreactive B cells and innate immune cells, such as NK cells, have also been reported to localize to the CNS from the periphery during MS pathology [179]. In the early stages of MS, peripheral humoral and innate immune cells accumulate in the perivascular and ventricular spaces that separate the blood vessels from the adjacent brain tissue, reactivated by local antigen presenting cells and subsequently move into the brain parenchyma to promote severe neuroinflammation [180]. These reactive immune cells release a plethora of inflammatory mediators, including nitric oxide, ROS and inflammatory cytokines, which impair neuronal function and activates CNS-resident astrocytes and microglia. Together, the continuous secretion of soluble inflammatory mediators promotes the development of a neurotoxic microenvironment that facilitates demyelination, axonal degeneration and oligodendrocyte and neuronal death.

One explanation for the development of autoreactive $\mathrm{T}$ and $\mathrm{B}$ cells is that some viral antigens presented by major histocompatibility complex II in the periphery or the CNS share homology with that of myelin components. Effector lymphocytes that enter the perivascular space are reactivated by antigen presenting cells presenting myelin peptides that share sequence and structural similarities 
with foreign-peptides [181]. This phenomenon, molecular mimicry, is considered a potential mechanism by which pathogens break self-immunological tolerance and induce an autoimmune reaction. Pathogens sharing high degrees of peptide similarity with myelin-derived peptides include Human Herpes virus type 6 and Epstein Barr virus [182]. The inflammatory milieu brought about by infiltrating innate immune cells and reactive $\mathrm{T}$ lymphocytes in the initial stages of the disease promotes further $\mathrm{T}$ cell polarization to the $\mathrm{T}_{\mathrm{H}} 1$ or $\mathrm{T}_{\mathrm{H}} 17$ subsets to amplify neuronal damage. From a genetic standpoint, single polymorphisms within specific candidate genes increase the susceptibility of individuals to developing MS. Such candidate genes may include genes located within the human leukocyte antigen (HLA) locus and immunological non-HLA genes involved in central tolerance, cytokine production and homeostatic proliferation [177].

Real time qPCR analysis of CNS tissue from MS patients has revealed that the ER stress markers ATF4, GRP78 and CHOP are significantly upregulated in the white matter of MS patients relative to tissue from nonMS individuals [183]. In agreement with these findings, a study performing detailed semiquantitative immunohistochemical and molecular analysis on multiple CNS cell-types in active MS lesions found that GRP78 and $\mathrm{CHOP}$ were highly upregulated in astrocytes, microglia and oligodendrocytes [184]. The elevated expression of UPR markers in MS lesions points toward a possible link between impaired ER proteostasis and the development of active lesions.

There are multiple potential events hypothesized to induce ER stress during MS. Glutamate excitotoxicity is an important mechanism that contributes to autoimmune demyelination and lesion formation [185]. Glutamate induces the expression of GRP78, and GRP78 knockdown leads to a significant increase in excitotoxicity-induced apoptosis [186]. This suggests that glutamate excitotoxicity promotes neuronal death through an ER stressdependent mechanism, and the upregulation of GRP78 helps neurons cope with the excessive amounts of glutamate. In accordance, GRP78 seems to be vital for maintaining cell survival during MS. Oligodendrocyteselective heterozygous deletion of GRP78 in mice induced with experimental autoimmune encephalomyelitis (EAE), an experimental model used to mimic the symptoms of MS, aggravates disease severity and enhances oligodendrocyte death [187].

Hypoxia is another potential ER stress inducer that is characteristic in, though not restricted to, MS. Histological evidence points toward a similar hypoxic-type response in diseased tissue of MS patients, as the hypoxia-related antigen D-110 is strongly expressed in tissue also expressing high levels of CHOP [184]. Alternatively, expression of human endogenous retrovirus
(HERV) envelop proteins may contribute to the pathology of MS by initiating neuroinflammatory and ER stress responses in the brain [12, 188]. For instance, the overexpression of the HERV envelope glycoprotein Syncytin-1 causes astrocytes to upregulate ER stress responses and the production of proinflammatory mediators that promote oligodendrocyte toxicity [12]. Finally, the inflammatory environment in the CNS could trigger ER stress in highly myelinating cells, such as oligodendrocytes. Due to their high demand for lipid synthesis, mature oligodendrocytes are more susceptible to ER stress when exposed to high levels of proinflammatory mediators. It was previously demonstrated that interferon (IFN) $-\gamma$ drives ER stress and cell death in oligodendrocytes both in vitro and in vivo [189]. In this same study, mice that were haploinsufficient for PERK were more susceptible to forced expression of IFN- $\gamma$, leading to myelination defects and oligodendrocyte death. Therefore, excessive neuroinflammation may induce ER stress in myelinating cells which would not only disrupt their ability to myelinate neuronal axons, but can also lead to cell death.

\section{ER stress-linked inflammation in neurodegenerative diseases}

The development of ER stress is considered an underlying factor contributing to the clinical manifestations linked to many neurodegenerative disorders. In addition to the diseases previously described, pathological processes associated with other neuropathologies, such as prion diseases [190-193], human immunodeficiency virus associatedneurocognitive disorders (HAND) [193, 194] and a variety of lysosomal storage diseases [195], promote cellular and physiological challenges which perturb ER homeostasis. A unifying feature of all of these diseases is the presence of neuroinflammation [2, 196-198]. While few studies have directly examined the interactions between ER stress and inflammation in the CNS, there is evidence that these processes are intimately linked [24, 199, 200].

In brain tissue, microglia and astrocytes collaborate to mediate inflammation by integrating environmental information and carrying out an appropriate response. Microglia are CNS-resident phagocytic cells derived from the yolk sac. These sentinels of the CNS are the principal innate immune cell in the brain and have a key role in orchestrating inflammatory responses [201-203]. Astrocytes are also considered important regulators of the CNS, as they assist in neuronal metabolism, synaptic transmission, lay down the barriers isolating the neural tissue of the brain and coordinate the finely-tuned events of neuroinflammation along with microglia [3]. These glial cells possess a diverse repertoire of innate receptors, such as scavenger receptors and pattern recognition receptors, which allow them to augment the 
expression of inflammatory cytokines and chemokines under metabolic stress or interaction with PAMPs or DAMPs [204, 205].

Extracellular protein aggregates or oligomers underlie the pathology of various neurodegenerative disorders, and act as "danger signals" released from apoptotic or necrotic neurons [2]. These pathological assemblies can be recognized by innate immune receptors residing on neighboring glial cells $[2,206]$. For example, $A \beta$ oligomers are perceived to act as ligands for both the TNF- $\alpha$ receptor and toll-like receptor 4 [207]. Transient substrate-receptor interaction promotes an inflammatory response that initiates debris clearance via phagocytosis by microglia [2]. However, chronic exposure to these DAMPs or internalization of abnormal protein aggregates alters the functional properties of immunocompetent microglia and astrocytes to promote a reactive phenotype $[2,208]$. In MS, autoreactive peripheral immune cells initiate an inflammatory response against myelin-derived antigen and promote neurotoxicity not only by compromising neuronal integrity directly, but causing astrocytes and microglia to secrete cytokines and other inflammatory mediators that contribute to demyelination [2, 209].

While chronic ER stress in neurons largely triggers signals to initiate apoptosis, extensive ER stress in glial cells has the potential to promote an inflammatory microenvironment characteristic in neurodegenerative diseases. Consistent with the role of astrocytes in mediating immunological homeostasis through its interactions with other cell types, the ER stress-induced upregulation in astrocytic inflammatory processes can encourage an inflammatory M1-like phenotype in microglia [92]. Similarly, neuronal ER stress has been shown to be positively correlated with microglial activation in a traumatic brain injury rat model [210]. ER stress not only influences pathways that result in the production of inflammatory mediators, but it also alters the responsiveness of cells to immunogenic stimuli. To this point, it has been documented that the administration of both prostaglandin $E_{2}$ and IFN- $\gamma$ synergizes with ER stress to increase the production of IL-6 in glial cells [211]. Likewise, TNF- $\alpha$ autocrine signaling during ER stress significantly enhances the apoptotic signals of the UPR [80].

PERK knockdown experiments suggest that the association between ER stressed astrocytes and microglia activation is initially dependent on PERK signaling in astrocytes [92]. PERK haploinsufficiency and partial PERK inhibition using the small molecule PERK inhibitor GSK2606414 selectively attenuates the production of ER stress-induced inflammatory cytokines and chemokines, including IL-6, C-C Motif Chemokine Ligand (CCL)2 and CCL20 [212]. Interestingly, treating ER stressed astrocytes with ISRIB, a compound which reverses the translational block of phosphorylated eIF $2 \alpha$, attenuates
ER stress-induced inflammatory gene expression [212]. We propose that the inflammatory signals induced during ER stress in astrocytes significantly relies on PERKdependent eIF2 $\alpha$ phosphorylation. These beneficial outcomes of PERK-eIF2 $\alpha$ modulation fall in line with previous studies demonstrating that treating priondiseased mice with GSK2606414 or ISRIB confers neuroprotection by partially recovering global translation rates $[213,214]$. Conversely, preventing eIF2 $\alpha$ dephosphorylation in response to tramatic brain injury using salubrinal is beneficial and attenuates neuroinflammation [11]. While it is becoming clear that PERK signaling has an important role in the regulation of neuroinflammation and neurodegeneration, a more complete understanding of the PERK-eIF2 $\alpha$ pathway is needed to define the context and cell-specific roles. Therefore, manipulating the PERK-eIF2 $\alpha$ axis without disturbing its homeostatic function could present an unappreciated way to alleviate aberrant neuroinflammation.

\section{Conclusion}

Many fundamental questions remain regarding the role of inflammation and ER stress in neurological diseases. Is inflammation beneficial or detrimental in neurodegenerative diseases? Most likely that it is important for tissue repair and neural regeneration, but detrimental when dysregulated. To complicate matters, the UPR system may be helpful or harmful depending on the level and spatial-temporal occurrence of ER stress. Cross-talk between the two programs may have beneficial functions through reciprocal regulation that promotes protective immunity. However, ER stress-induced amplification of inflammation may worsen chronic diseases [215].

Our understanding on if and how ER stress directly provokes an inflammatory reaction in neurodegenerative diseases remains to be clarified. Studies from our laboratory demonstrate that ER stress generated in murine astrocytes encourages PERK-dependent inflammatory signaling in vitro, suggesting that astrocytes themselves are potential contributors to neurotoxic inflammation in the face of ER dysfunction [92, 212]. Nevertheless, the relevance of these findings as it pertains to animal models and patients remains to be determined. Further, whether microglia respond to ER stress in the same vain has yet to be explored. Investigators must be cognizant of how agents used to manipulate the UPR will impinge on its homeostatic roles when devising pharmacological approaches to treat neurodegenerative diseases. Moreover, since both defective and chronic UPR signaling contribute to neuronal death in disease, developing agents which strictly attenuate pathways elicited by the ER stress response are insufficient. It is likely that targeting specific signaling components of the UPR that are predicted to enhance the pro-survival signals of the UPR 
or attenuate its inflammatory/apoptotic responses will possess more favorable outcomes.

In summary, ER stress and neuroinflammation are common pathological features of neurodegenerative diseases, and the mechanisms by which they interact during neurodegeneration remain to be elucidated. Further knowledge of this cross-talk will help us understand whether targeting cell stress pathways, such as ER stress in neurodegeneration, can control aberrant neuroinflammation and treat neurological disorders. To date, many studies have demonstrated beneficial effects of modulating ER stress pathways either genetically or pharmacologically in model organisms. However, the looming question remains: will targeting the UPR pathways be safe and beneficial in patients?

\begin{abstract}
Abbreviations
AD: Alzheimer's disease; ALS: Amyotrophic Lateral Sclerosis; AP-1: Activator protein 1; APP: A $\beta$ precursor protien; ASK1: Apoptosis signal-regulating kinase 1; ATF: Activating transcription factor; $A \beta$ : Amyloid- $\beta$; BBB: Blood brain barrier; BiP: binding immunoglobulin protein; bZIP: basic leucine zipper; CHOP: CCAAT-enhancer-binding protein homologous protein; CNS: Central nervous system; DAMP: danger-associated molecular patterns;

elF2a: eukaryotic translation initiation factor 2a; ER: Endoplasmic reticulum; ERAD: ER-associated degradation; Ero1a: ER oxidoreductase a; FAD: Familial Alzheimer's disease; GADD34: Growth arrest and DNA damage-inducible protein 34; GCN2: General control non-derepressible 2; GRP: Glucose-regulated protein; GSK-3: Glycogen synthase kinase 3; HERV: human endogenous retrovirus; HLA: Human leukocyte antigen; IFN- $\gamma$ : Interferon- $\gamma$; IKK: IKB kinase; IL: Interleukin; IRE-1a: Inositol-requiring 1a; IKB: inhibitors of $\mathrm{KB} ;$; JAK1: Januse kinase 1; JNK: c-Jun N-terminal kinase; Keap1: Kelch-like ECH-associated protein 1; LRRK2: Leucine-rich repeat kinase 2; MAPK: Mitogen activated protein kinase; MEF: Mouse embryonic fibroblasts; MS: Multiple Sclerosis;

NFT: Neurofibrillary tangle; NF-kB: Nuclear factor kappa-light-chain-enhancer of activated B cells; NOD1/2: Nucleotide-binding oligomerization domain 1/2; Nrf-2: Nuclear factor-like 2; PAMP: pathogen-associated molecular patterns; PD: Parkinson's disease; PDI: Protein disulphide isomerase; PERK: Doublestranded RNA dependent protein kinase-like ER kinase; PKR: Double stranded RNA-dependent kinase; PPI: Protein phosphatase 1; PS: Presenilin; RIDD: Regulated IRE1-dependent decay; RIPK2: Receptor-interacting serine/ threonine-protein kinase 2; RNase: Endoribonuclease; RNS: Reactive nitrogen species; ROS: Reactive oxygen species; SRP: Signal-recognition particle; STAT: Signal transducers and activators of transcription; sXBP1: Spliced $x$-boxbinding protein 1; TNF-a: Tumor-necrosis factor-a; TRAF2: TNF-a-receptorassociated factor 2; UPR: Unfolded protein response; WT: Wild-type; XBP1: Xbox-binding protein 1
\end{abstract}

\section{Acknowledgements}

Not applicable.

\section{Funding}

The authors received funding from a Career Transition Award from the National Multiple Sclerosis Society (NMSS) (TA 3050-A-1), the West Virginia Clinical and Translational Science Institute (NIGMS U54GM104942) and the West Virginia Stoke CoBRE (NIGMS P20 GM109098).

\section{Availability of data and materials}

Data sharing is not applicable to this article as no datasets were generated or analyzed during the current study.

\section{Authors' contributions}

NS performed the literature review and wrote the manuscript under the advisement of GM. NS, CS and SS graphed the illustrations and contributed to the content of the manuscript. GM edited the manuscript. All authors reviewed the manuscript before submission. All authors read and approved the final manuscript.

\section{Authors' information}

Not applicable.

\section{Competing interests}

The authors declare that they have no competing interests.

\section{Consent for publication}

Not applicable.

\section{Ethics approval and consent to participate}

This review summarizes published studies using human and animal material. Research studies in this review were approved by the appropriate ethics committees.

Received: 7 December 2016 Accepted: 17 May 2017

Published online: 25 May 2017

\section{References}

1. Heneka MT, Kummer MP, Latz E. Innate immune activation in neurodegenerative disease. Nat Rev Immunol. 2014;14(7):463-77.

2. Glass CK, Saijo K, Winner B, Marchetto MC, Gage FH. Mechanisms underlying inflammation in neurodegeneration. Cell. 2010;140(6):918-34.

3. Sofroniew MV. Astrocyte barriers to neurotoxic inflammation. Nat Rev Neurosci. 2015;16(5):249-63.

4. Prinz M, Priller J. Microglia and brain macrophages in the molecular age: from origin to neuropsychiatric disease. Nat Rev Neurosci. 2014;15(5):300-12.

5. Block ML, Hong JS. Microglia and inflammation-mediated neurodegeneration: multiple triggers with a common mechanism. Prog Neurobiol. 2005;76(2):77-98.

6. Perry VH, Nicoll JA, Holmes C. Microglia in neurodegenerative disease. Nat Rev Neurol. 2010;6(4):193-201.

7. DiSabato DJ, Quan N, Godbout JP. Neuroinflammation: the devil is in the details. J Neurochem. 2016;139(Suppl 2):136-53.

8. Lee KM, MacLean AG. New advances on glial activation in health and disease. World J Virol. 2015;4(2):42-55.

9. Hetz C, Mollereau B. Disturbance of endoplasmic reticulum proteostasis in neurodegenerative diseases. Nat Rev Neurosci. 2014;15(4):233-49.

10. Bellezza I, Grottelli S, Mierla AL, Cacciatore I, Fornasari E, Roscini L, et al. Neuroinflammation and endoplasmic reticulum stress are coregulated by cyclo(his-pro) to prevent LPS neurotoxicity. Int J Biochem Cell Biol. 2014;51: 159-69.

11. Logsdon AF, Lucke-Wold BP, Nguyen L, Matsumoto RR, Turner RC, Rosen $\mathrm{CL}$, et al. Salubrinal reduces oxidative stress, neuroinflammation and impulsive-like behavior in a rodent model of traumatic brain injury. Brain Res. 2016;1643:140-51.

12. Deslauriers AM, Afkhami-Goli A, Paul AM, Bhat RK, Acharjee S, Ellestad KK, et al. Neuroinflammation and endoplasmic reticulum stress are coregulated by crocin to prevent demyelination and neurodegeneration. J Immunol. 2011; 187(9):4788-99.

13. Salminen A, Kauppinen A, Suuronen T, Kaarniranta K, Ojala J. ER stress in Alzheimer's disease: a novel neuronal trigger for inflammation and Alzheimer's pathology. J Neuroinflammation. 2009;6:41.

14. Drake TM. Unfolding the promise of translational targeting in neurodegenerative disease. NeuroMolecular Med. 2015;17(2):147-57.

15. Schechter I. Partial amino acid sequence of the precursor of immunoglobulin light chain programmed by messenger RNA in vitro. Science. 1975;188(4184):160-2.

16. Nyathi Y, Wilkinson BM, Pool MR. Co-translational targeting and translocation of proteins to the endoplasmic reticulum. Biochim Biophys Acta. 2013;1833(11):2392-402.

17. Siegel $V$, Walter $P$. Each of the activities of signal recognition particle (SRP) is contained within a distinct domain: analysis of biochemical mutants of SRP. Cell. 1988;52(1):39-49.

18. Walter P, Blobel G. Translocation of proteins across the endoplasmic reticulum. II. Signal recognition protein (SRP) mediates the selective binding to microsomal membranes of in-vitro-assembled polysomes synthesizing secretory protein. J Cell Biol. 1981;91(2 Pt 1):551-6.

19. Black $B L$, Jarett $L, M c D o n a l d ~ J M$. The regulation of endoplasmic reticulum calcium uptake of adipocytes by cytoplasmic calcium. J Biol Chem. 1981; 256(1):322-9. 
20. Kim I, Xu W, Reed JC. Cell death and endoplasmic reticulum stress: disease relevance and therapeutic opportunities. Nat Rev Drug Discov. 2008;7(12):1013-30.

21. Tu BP, Weissman JS. Oxidative protein folding in eukaryotes: mechanisms and consequences. J Cell Biol. 2004;164(3):341-6.

22. Gomez-Navarro N, Miller EA. COP-coated vesicles. Curr Biol. 2016;26(2):R54-7.

23. Ellgaard L, McCaul N, Chatsisvili A, Braakman I. Co- and post-translational protein folding in the ER. Traffic. 2016;17(6):615-38.

24. Zhang K, Kaufman RJ. From endoplasmic-reticulum stress to the inflammatory response. Nature. 2008;454(7203):455-62.

25. Sun S, Shi G, Sha H, Ji Y, Han X, Shu X, et al. IRE1 a is an endogenous substrate of endoplasmic-reticulum-associated degradation. Nat Cell Biol. 2015;17(12):1546-55.

26. Harding $H$, Zhang $Y$, Ron D. Protein translation and folding are coupled by an endoplasmic-reticulum-resident kinase. Nature. 1999:397(6716):271-4.

27. Shore GC, Papa FR, Oakes SA. Signaling cell death from the endoplasmic reticulum stress response. Curr Opin Cell Biol. 2011;23(2):143-9.

28. Hitomi J, Katayama T, Eguchi $Y$, Kudo T, Taniguchi M, Koyama Y, et al. Involvement of caspase-4 in endoplasmic reticulum stress-induced apoptosis and Abeta-induced cell death. J Cell Biol. 2004;165(3):347-56.

29. Egger L, Schneider J, Rheme C, Tapernoux M, Hacki J, Borner C. Serine proteases mediate apoptosis-like cell death and phagocytosis under caspase-inhibiting conditions. Cell Death Differ. 2003;10(10):1188-203.

30. Li J, Ni M, Lee B, Barron E, Hinton DR, Lee AS. The unfolded protein response regulator GRP78/BiP is required for endoplasmic reticulum integrity and stress-induced autophagy in mammalian cells. Cell Death Differ. 2008;15(9):1460-71.

31. Bertolotti A, Zhang Y, Hendershot LM, Harding HP, Ron D. Dynamic interaction of BiP and ER stress transducers in the unfolded-protein response. Nat Cell Biol. 2000;2(6):326-32.

32. Shen J, Chen $X$, Hendershot $L$, Prywes R. ER stress regulation of ATF6 localization by dissociation of BiP/GRP78 binding and unmasking of Golgi localization signals. Dev Cell. 2002;3(1):99-111.

33. Janssens S, Pulendran B, Lambrecht BN. Emerging functions of the unfolded protein response in immunity. Nat Immunol. 2014;15(10):910-9.

34. Credle JJ, Finer-Moore JS, Papa FR, Stroud RM, Walter P. On the mechanism of sensing unfolded protein in the endoplasmic reticulum. Proc Natl Acad Sci U S A. 2005;102(52):18773-84.

35. Ron D, Walter $P$. Signal integration in the endoplasmic reticulum unfolded protein response. Nat Rev Mol Cell Biol. 2007;8(7):519-29.

36. Haze $\mathrm{K}$, Yoshida $\mathrm{H}$, Yanagi H, Yura T, Mori K. Mammalian transcription factor ATF6 is synthesized as a transmembrane protein and activated by proteolysis in response to endoplasmic reticulum stress. Mol Biol Cell. 1999; 10(11):3787-99.

37. Schröder M, Kaufman R. The mammalian unfolded protein response. Annu Rev Biochem. 2005;74:739-89.

38. Ye J, Rawson R, Komuro R, Chen X, Davé U, Prywes R, et al. ER stress induces cleavage of membrane-bound ATF6 by the same proteases that process SREBPs. Mol Cell. 2000;6(6):1355-64

39. Yamamoto $K$, Sato T, Matsui T, Sato M, Okada T, Yoshida $H$, et al. Transcriptional induction of mammalian ER quality control proteins is mediated by single or combined action of ATF6alpha and XBP1. Dev Cell. 2007;13(3):365-76.

40. Sidrauski $C$, Walter $P$. The transmembrane kinase Ire1 $p$ is a site-specific endonuclease that initiates mRNA splicing in the unfolded protein response. Cell. 1997:90(6):1031-9.

41. Lee KP, Dey M, Neculai D, Cao C, Dever TE, Sicheri F. Structure of the dual enzyme Ire 1 reveals the basis for catalysis and regulation in nonconventional RNA splicing. Cell. 2008;132(1):89-100

42. Tirasophon W, Lee K, Callaghan B, Welihinda A, Kaufman RJ. The endoribonuclease activity of mammalian IRE1 autoregulates its mRNA and is required for the unfolded protein response. Genes Dev. 2000;14(21):2725-36.

43. Lee K, Tirasophon W, Shen X, Michalak M, Prywes R, Okada T, et al. IRE1mediated unconventional mRNA splicing and S2P-mediated ATF6 cleavage merge to regulate XBP1 in signaling the unfolded protein response. Genes Dev. 2002;16(4):452-66

44. Yamamoto K, Yoshida H, Kokame K, Kaufman RJ, Mori K. Differentia contributions of ATF6 and XBP1 to the activation of endoplasmic reticulum stress-responsive cis-acting elements ERSE, UPRE and ERSE-IIUPRE and ERSEII. J Biochem. 2004;136(3):343-50.

45. Maurel M, Chevet E, Tavernier J, Gerlo S. Getting RIDD of RNA: IRE1 in cell fate regulation. Trends Biochem Sci. 2014;39(5):245-54.
46. Hollien J, Weissman JS. Decay of endoplasmic reticulum-localized mRNAs during the unfolded protein response. Science. 2006;313(5783):104-7.

47. Han D, Lerner AG, Vande Walle L, Upton JP, Xu W, Hagen A, et al. IRE1alpha kinase activation modes control alternate endoribonuclease outputs to determine divergent cell fates. Cell. 2009;138(3):562-75.

48. Upton JP, Wang L, Han D, Wang ES, Huskey NE, Lim L, et al. IRE1alpha cleaves select microRNAs during ER stress to derepress translation of proapoptotic Caspase-2. Science. 2012;338(6108):818-22.

49. Chen Y, Brandizzi F. IRE1: ER stress sensor and cell fate executor. Trends Cell Bio. 2013;23(11):547-55.

50. Starck SR, Tsai JC, Chen K, Shodiya M, Wang L, Yahiro K, Martins-Green M, Shastri N, Walter P: Translation from the $5^{\prime}$ untranslated region shapes the integrated stress response. Science 2016, 351(6272):aad3867.

51. Klann E, Dever TE. Biochemical mechanisms for translational regulation in synaptic plasticity. Nat Rev Neurosci. 2004:5(12):931-42.

52. Vattem KM, Wek RC. Reinitiation involving upstream ORFs regulates ATF4 mRNA translation in mammalian cells. Proc Natl Acad Sci U S A. 2004; 101(31):11269-74

53. Wang M, Kaufman RJ. Protein misfolding in the endoplasmic reticulum as a conduit to human disease. Nature. 2016;529(7586):326-35.

54. Nishitoh H. CHOP is a multifunctional transcription factor in the ER stress response. J Biochem. 2012;151(3):217-9.

55. Oyadomari S, Mori M. Roles of CHOP/GADD153 in endoplasmic reticulum stress. Cell Death Differ. 2004;11(4):381-9.

56. Tabas I, Ron D. Integrating the mechanisms of apoptosis induced by endoplasmic reticulum stress. Nat Cell Biol. 2011;13(3):184-90.

57. Li G, Mongillo M, Chin K-T, Harding H, Ron D, Marks AR, et al. Role of ERO1alpha-mediated stimulation of inositol 1,4,5-triphosphate receptor activity in endoplasmic reticulum stress-induced apoptosis. J Cell Biol. 2009;186(6): 783-92.

58. Görlach A, Klappa P, Kietzmann T. The endoplasmic reticulum: folding, calcium homeostasis, signaling, and redox control. Antioxid Redox Signal. 2006;8(9-10):1391-418.

59. Hansson MJ, Mansson R, Morota S, Uchino H, Kallur T, Sumi T, et al. Calcium-induced generation of reactive oxygen species in brain mitochondria is mediated by permeability transition. Free Radic Biol Med. 2008;45(3):284-94.

60. Gross E, Sevier CS, Heldman N, Vitu E, Bentzur M, Kaiser CA, et al. Generating disulfides enzymatically: reaction products and electron acceptors of the endoplasmic reticulum thiol oxidase Ero1p. Proc Natl Acad Sci U S A. 2006;103(2):299-304.

61. Brush MH, Weiser DC, Shenolikar S. Growth arrest and DNA damageinducible protein GADD34 targets protein phosphatase 1 alpha to the endoplasmic reticulum and promotes dephosphorylation of the alpha subunit of eukaryotic translation initiation factor 2. Mol Cell Biol. 2003;23(4): 1292-303.

62. Marciniak $S$, Yun C, Oyadomari $S$, Novoa I, Zhang $Y$, Jungreis $R$, et al. CHOP induces death by promoting protein synthesis and oxidation in the stressed endoplasmic reticulum. Genes Dev. 2004;18(24):3066-77.

63. Urra H, Dufey E, Lisbona F, Rojas-Rivera D, Hetz C. When ER stress reaches a dead end. Biochim Biophys Acta. 2013;1833(12):3507-17.

64. Hollander MC, Zhan Q, Bae I, Fornace AJ. Mammalian GADD34, an apoptosis- and DNA damage-inducible gene. J Biol Chem. 1997;272(21): 13731-7.

65. Cullinan SB, Diehl JA. PERK-dependent activation of Nrf2 contributes to redox homeostasis and cell survival following endoplasmic reticulum stress. J Biol Chem. 2004;279(19):20108-17.

66. Cullinan SB, Zhang D, Hannink M, Arvisais E, Kaufman RJ, Diehl JA. Nrf2 is a direct PERK substrate and effector of PERK-dependent cell survival. Mol Cell Biol. 2003;23(20):7198-209.

67. Yoshida H, Matsui T, Yamamoto A, Okada T, Mori K. XBP1 mRNA is induced by ATF6 and spliced by IRE1 in response to ER stress to produce a highly active transcription factor. Cell. 2001;107(7):881-91.

68. Tsuru A, Imai Y, Saito M, Kohno K. Novel mechanism of enhancing IRE1alpha-XBP1 signalling via the PERK-ATF4 pathway. Sci Rep. 2016;6:24217

69. Yoshida H, Okada T, Haze K, Yanagi H, Yura T, Negishi M, et al. ATF6 activated by proteolysis binds in the presence of NF-Y (CBF) directly to the cis-acting element responsible for the mammalian unfolded protein response. Mol Cell Biol. 2000;20(18):6755-67.

70. Cnop M. Foufelle F, Velloso LA. Endoplasmic reticulum stress, obesity and diabetes. Trends Mol Med. 2012;18(1):59-68. 
71. Bommiasamy H, Back SH, Fagone P, Lee K, Meshinchi S, Vink E, et al. ATF6alpha induces XBP1-independent expansion of the endoplasmic reticulum. J Cell Sci. 2009;122(Pt 10):1626-36.

72. Trinh MA, Klann E. Translational control by elF2a kinases in long-lasting synaptic plasticity and long-term memory. Neurobiol Learn Mem. 2013;105: 93-9.

73. Martínez G, Vidal RL, Mardones P, Serrano FG, Ardiles AO, Wirth C, et al. Regulation of memory formation by the transcription factor XBP1. Cell Rep. 2016;14(6):1382-94.

74. Tang G, Minemoto Y, Dibling B, Purcell NH, Li Z, Karin M, et al. Inhibition of JNK activation through NF-kappaB target genes. Nature. 2001;414(6861): 313-7.

75. Gilmore TD. Introduction to NF-kappaB: players, pathways, perspectives. Oncogene. 2006;25(51):6680-4.

76. Chen Z, Hagler J, Palombella VJ, Melandri F, Scherer D, Ballard D, et al. Signal-induced site-specific phosphorylation targets I kappa B alpha to the ubiquitin-proteasome pathway. Genes Dev. 1995:9(13):1586-97.

77. Tabary O, Boncoeur E, de Martin R, Pepperkok R, Clement A, Schultz C, et al. Calcium-dependent regulation of NF-(kappa)B activation in cystic fibrosis airway epithelial cells. Cell Signal. 2006;18(5):652-60.

78. van den Berg $\mathrm{R}$, Haenen GR, van den Berg H, Bast A. Transcription factor NF-kappaB as a potential biomarker for oxidative stress. Br J Nutr. 2001; 86(Suppl 1):S121-7.

79. Deng J, Lu PD, Zhang Y, Scheuner D, Kaufman RJ, Sonenberg N, et al. Translational repression mediates activation of nuclear factor kappa B by phosphorylated translation initiation factor 2. Mol Cell Biol. 2004;24(23):10161-8.

80. Hu P, Han Z, Couvillon AD, Kaufman RJ, Exton JH. Autocrine tumor necrosis factor alpha links endoplasmic reticulum stress to the membrane death receptor pathway through IRE1alpha-mediated NF-kappaB activation and down-regulation of TRAF2 expression. Mol Cell Biol. 2006;26(8):3071-84.

81. Urano F, Wang X, Bertolotti A, Zhang Y, Chung P, Harding H, et al. Coupling of stress in the ER to activation of JNK protein kinases by transmembrane protein kinase IRE1. Science. 2000;287(5453):664-6.

82. Shaulian E, Karin M. AP-1 as a regulator of cell life and death. Nat Cell Biol. 2002;4(5):E131-6.

83. Keestra-Gounder AM, Byndloss MX, Seyffert N, Young BM, Chávez-Arroyo A, Tsai AY, et al. NOD1 and NOD2 signalling links ER stress with inflammation. Nature. 2016:532(7599):394-7.

84. Hetz C, Bernasconi P, Fisher J, Lee A-H, Bassik MC, Antonsson B, et al. Proapoptotic BAX and BAK modulate the unfolded protein response by a direct interaction with IRE1alpha. Science. 2006;312(5773):572-6.

85. Lamkanfi M, Kalai M, Vandenabeele P. Caspase-12: an overview. Cell Death Differ. 2004;11(4):365-8.

86. Yang C, Diiorio P, Jurczyk A, O'Sullivan-Murphy B, Urano F, Bortell R. Pathological endoplasmic reticulum stress mediated by the IRE1 pathway contributes to pre-insulitic beta cell apoptosis in a virus-induced rat model of type 1 diabetes. Diabetologia. 2013;56(12):2638-46.

87. Fischer H, Koenig U, Eckhart L, Tschachler E. Human caspase 12 has acquired deleterious mutations. Biochem Biophys Res Commun. 2002 293(2):722-6.

88. Wang $X Z$, Ron D. Stress-induced phosphorylation and activation of the transcription factor CHOP (GADD153) by p38 MAP Kinase. Science. 1996; 272(5266):1347-9.

89. Lei K, Davis RJ. JNK phosphorylation of Bim-related members of the $\mathrm{BCl} 2$ family induces Bax-dependent apoptosis. Proc Natl Acad Sci U S A. 2003, 100(5):2432-7

90. Hosoi T, Sasaki M, Miyahara T, Hashimoto C, Matsuo S, Yoshii M, et al. Endoplasmic reticulum stress induces leptin resistance. Mol Pharmacol. 2008;74(6):1610-9.

91. Flores-Morales A, Fernandez L, Rico-Bautista E, Umana A, Negrin C, Zhang $J G$, et al. Endoplasmic reticulum stress prolongs $G H$-induced Janus kinase (JAK2)/signal transducer and activator of transcription (STAT5) signaling pathway. Mol Endocrinol. 2001;15(9):1471-83.

92. Meares GP, Liu Y, Rajbhandari R, Qin H, Nozell SE, Mobley JA, et al. PERKdependent activation of JAK1 and STAT3 contributes to endoplasmic reticulum stress-induced inflammation. Mol Cell Biol. 2014;34(20):3911-25.

93. Lin JH, Li H, Yasumura D, Cohen HR, Zhang C, Panning B, et al. IRE1 signaling affects cell fate during the unfolded protein response. Science. 2007;318(5852):944-9.

94. Wang M, Kaufman RJ. The impact of the endoplasmic reticulum protein-folding environment on cancer development. Nat Rev Cancer. 2014;14(9):581-97.
95. Rutkowski DT, Arnold SM, Miller CN, Wu J, Li J, Gunnison KM, et al. Adaptation to ER stress is mediated by differential stabilities of pro-survival and pro-apoptotic mRNAs and proteins. PLoS Biol. 2006;4(11):e374.

96. Inagi R, Kumagai T, Nishi H, Kawakami T, Miyata T, Fujita T, et al. Preconditioning with endoplasmic reticulum stress ameliorates mesangioproliferative glomerulonephritis. J Am Soc Nephrol. 2008;19(5):915-22.

97. Mercado G, Valdes P, Hetz C. An ERcentric view of Parkinson's disease. Trends Mol Med. 2013;19(3):165-75.

98. Fouillet A, Levet C, Virgone A, Robin M, Dourlen P, Rieusset J, et al. ER stress inhibits neuronal death by promoting autophagy. Autophagy. 2012;8(6): 915-26.

99. Calabrese V, Cornelius C, Dinkova-Kostova AT, Calabrese EJ, Mattson MP. Cellular stress responses, the hormesis paradigm, and vitagenes: novel targets for therapeutic intervention in neurodegenerative disorders. Antioxid Redox Signal. 2010;13(11):1763-811.

100. Reitz C, Brayne C, Mayeux R. Epidemiology of Alzheimer disease. Nat Rev Neurol. 2011;7(3):137-52

101. De Strooper B. Proteases and proteolysis in Alzheimer disease: a multifactorial view on the disease process. Physiol Rev. 2010;90(2):465-94.

102. Jucker M, Walker LC. Self-propagation of pathogenic protein aggregates in neurodegenerative diseases. Nature. 2013;501(7465):45-51.

103. Caceres A, Kosik KS. Inhibition of neurite polarity by tau antisense oligonucleotides in primary cerebellar neurons. Nature. 1990;343(6257):461-3.

104. Stoothoff WH, Johnson GV. Tau phosphorylation: physiological and pathological consequences. Biochim Biophys Acta. 2005;1739(2-3):280-97.

105. Gong CX, lqbal K. Hyperphosphorylation of microtubule-associated protein tau: a promising therapeutic target for Alzheimer disease. Curr Med Chem. 2008;15(23):2321-8.

106. Veugelen S, Saito T, Saido TC, Chávez-Gutiérrez L, De Strooper B. Familial Alzheimer's disease mutations in Presenilin generate Amyloidogenic $A \beta$ peptide seeds. Neuron. 2016;90(2):410-6.

107. Weggen S, Beher D. Molecular consequences of amyloid precursor protein and presenilin mutations causing autosomal-dominant Alzheimer's disease. Alzheimers Res Ther. 2012:4(2):9.

108. Mawuenyega KG, Sigurdson W, Ovod V, Munsell L, Kasten T, Morris JC, et al. Decreased clearance of CNS beta-amyloid in Alzheimer's disease. Science. 2010;330(6012):1774

109. Duran-Aniotz C, Martinez G, Hetz C. Memory loss in Alzheimer's disease: are the alterations in the UPR network involved in the cognitive impairment? Front Aging Neurosci. 2014;6:8

110. Lourenco MV, Clarke JR, Frozza RL, Bomfim TR, Forny-Germano L, Batista AF, et al. TNF-alpha mediates PKR-dependent memory impairment and brain IRS-1 inhibition induced by Alzheimer's beta-amyloid oligomers in mice and monkeys. Cell Metab. 2013;18(6):831-43.

111. Ma T, Trinh MA, Wexler AJ, Bourbon C, Gatti E, Pierre P, et al. Suppression of elF2a kinases alleviates Alzheimer's disease-related plasticity and memory deficits. Nat Neurosci. 2013;16(9):1299-305.

112. Costa-Mattioli M, Sossin WS, Klann E, Sonenberg N. Translational control of long-lasting synaptic plasticity and memory. Neuron. 2009;61(1):10-26.

113. Cissé M, Duplan E, Lorivel T, Dunys J, Bauer C, Meckler X, et al. The transcription factor XBP1s restores hippocampal synaptic plasticity and memory by control of the Kalirin-7 pathway in Alzheimer model. Mol Psychiatry. 2016;

114. Segev Y, Barrera I, Ounallah-Saad H, Wibrand K, Sporild I, Livne A, et al. PKR inhibition rescues memory deficit and ATF4 Overexpression in ApoE epsilon4 human replacement mice. J Neurosci. 2015:35(38):12986-93.

115. Bomfim TR, Forny-Germano L, Sathler LB, Brito-Moreira J, Houzel JC, Decker $H$, et al. An anti-diabetes agent protects the mouse brain from defective insulin signaling caused by Alzheimer's disease- associated Abeta oligomers. J Clin Invest. 2012;122(4):1339-53.

116. Ferreiro E, Oliveira CR, Pereira C. Involvement of endoplasmic reticulum Ca2 + release through ryanodine and inositol 1,4,5-triphosphate receptors in the neurotoxic effects induced by the amyloid-beta peptide. J Neurosci Res. 2004;76(6):872-80

117. Paula-Lima AC, Adasme T, SanMartín C, Sebollela A, Hetz C, Carrasco MA, et al. Amyloid $\beta$-peptide oligomers stimulate RyR-mediated $\mathrm{Ca} 2+$ release inducing mitochondrial fragmentation in hippocampal neurons and prevent RyR-mediated dendritic spine remodeling produced by BDNF. Antioxid Redox Signal. 2011;14(7):1209-23.

118. Demuro A, Parker I. Cytotoxicity of intracellular a 342 amyloid oligomers involves $\mathrm{Ca} 2+$ release from the endoplasmic reticulum by stimulated production of inositol trisphosphate. J Neurosci. 2013;33(9):3824-33. 
119. Abisambra JF, Jinwal UK, Blair LJ, O'Leary JC, Li Q, Brady S, et al. Tau accumulation activates the unfolded protein response by impairing endoplasmic reticulum-associated degradation. J Neurosci. 2013;33(22): 9498-507.

120. Nijholt DAT, Nölle A, van Haastert ES, Edelijn H, Toonen RF, Hoozemans JJM, et al. Unfolded protein response activates glycogen synthase kinase-3 via selective lysosomal degradation. Neurobiol Aging. 2013;34(7):1759-71.

121. Resende R, Ferreiro E, Pereira C, Oliveira C. ER stress is involved in Abetainduced GSK-3beta activation and tau phosphorylation. J Neurosci Res. 2008;86(9):2091-9.

122. Ho Y-S, Yang $X$, Lau JC-F, Hung CH-L, Wuwongse $S$, Zhang Q, et al. Endoplasmic reticulum stress induces tau pathology and forms a vicious cycle: implication in Alzheimer's disease pathogenesis. J Alzheimers Dis. 2012;28(4):839-54.

123. Lasagna-Reeves CA, Castillo-Carranza DL, Guerrero-Muoz MJ, Jackson GR, Kayed R. Preparation and characterization of neurotoxic tau oligomers. Biochemistry. 2010:49(47):10039-41.

124. Katayama T, Imaizumi K, Sato N, Miyoshi K, Kudo T, Hitomi J, et al. Presenilin-1 mutations downregulate the signalling pathway of the unfolded-protein response. Nat Cell Biol. 1999;1(8):479-85.

125. Katayama T, Imaizumi K, Honda A, Yoneda T, Kudo T, Takeda M, et al. Disturbed activation of endoplasmic reticulum stress transducers by familial Alzheimer's disease-linked presenilin-1 mutations. J Biol Chem. 2001;276(46):43446-54.

126. Sato N, Imaizumi K, Manabe T, Taniguchi M, Hitomi J, Katayama T, et al. Increased production of beta-amyloid and vulnerability to endoplasmic reticulum stress by an aberrant spliced form of presenilin 2. J Biol Chem. 2001;276(3):2108-14.

127. Paschen W, Mengesdorf T. Endoplasmic reticulum stress response and neurodegeneration. Cell Calcium. 2005;38(3-4):409-15.

128. Mattson MP, Zhu H, Yu J, Kindy MS. Presenilin-1 mutation increases neuronal vulnerability to focal ischemia in vivo and to hypoxia and glucose deprivation in cell culture: involvement of perturbed calcium homeostasis. J Neurosci. 2000;20(4):1358-64.

129. Zatti G, Ghidoni R, Barbiero L, Binetti G, Pozzan T, Fasolato C, et al. The presenilin 2 M239l mutation associated with familial Alzheimer's disease reduces Ca2+ release from intracellular stores. Neurobiol Dis. 2004;15(2):269-78.

130. Sato N, Urano F, Yoon Leem J, Kim SH, Li M, Donoviel D, et al. Upregulation of $\mathrm{BiP}$ and $\mathrm{CHOP}$ by the unfolded-protein response is independent of presenilin expression. Nat Cell Biol. 2000;2(12):863-70.

131. Hartmann A, Hunot S, Michel PP, Muriel MP, Vyas S, Faucheux BA, et al. Caspase-3: a vulnerability factor and final effector in apoptotic death of dopaminergic neurons in Parkinson's disease. Proc Natl Acad Sci U S A. 2000;97(6):2875-80.

132. Schildknecht S, Gerding HR, Karreman C, Drescher M, Lashuel HA, Outeiro TF, et al. Oxidative and nitrative alpha-synuclein modifications and proteostatic stress: implications for disease mechanisms and interventions in synucleinopathies. J Neurochem. 2013;125(4):491-511.

133. Chartier-Harlin MC, Kachergus J, Roumier C, Mouroux V, Douay X, Lincoln S, et al. Alpha-synuclein locus duplication as a cause of familial Parkinson's disease. Lancet. 2004;364(9440):1167-9.

134. Michel PP, Hirsch EC, Hunot S. Understanding Dopaminergic cell death pathways in Parkinson disease. Neuron. 2016;90(4):675-91.

135. Scarffe LA, Stevens DA, Dawson VL, Dawson TM. Parkin and PINK1: much more than mitophagy. Trends Neurosci. 2014;37(6):315-24.

136. Corti O, Brice A. Mitochondrial quality control turns out to be the principal suspect in parkin and PINK1-related autosomal recessive Parkinson's disease. Curr Opin Neurobiol. 2013;23(1):100-8.

137. Pickrell AM, Youle RJ. The roles of PINK1, parkin, and mitochondrial fidelity in Parkinson's disease. Neuron. 2015;85(2):257-73.

138. Zimprich A, Biskup S, Leitner $P$, Lichtner $P$, Farrer $M$, Lincoln S, et al. Mutations in LRRK2 cause autosomal-dominant parkinsonism with pleomorphic pathology. Neuron. 2004;44(4):601-7.

139. Lee BD, Shin J-H, VanKampen J, Petrucelli L, West AB, Ko HS, et al. Inhibitors of leucine-rich repeat kinase-2 protect against models of Parkinson's disease. Nat Med. 2010;16(9):998-1000.

140. Ryu EJ, Harding HP, Angelastro JM, Vitolo OV, Ron D, Greene LA. Endoplasmic reticulum stress and the unfolded protein response in cellular models of Parkinson's disease. J Neurosci. 2002;22(24):10690-8.

141. Chung CY, Khurana V, Auluck PK, Tardiff DF, Mazzulli JR, Soldner F, et al. Identification and rescue of a-synuclein toxicity in Parkinson patient-derived neurons. Science. 2013;342(6161):983-7.
142. Uehara T, Nakamura T, Yao D, Shi Z-Q, Gu Z, Ma Y, et al. S-nitrosylated protein-disulphide isomerase links protein misfolding to neurodegeneration. Nature. 2006;441(7092):513-7.

143. Colla E, Jensen PH, Pletnikova O, Troncoso JC, Glabe C, Lee MK. Accumulation of toxic alpha-synuclein oligomer within endoplasmic reticulum occurs in alpha-synucleinopathy in vivo. J Neurosci. 2012;32(10):3301-5.

144. Cooper AA, Gitler AD, Cashikar A, Haynes CM, Hill KJ, Bhullar B, et al. Alphasynuclein blocks ER-Golgi traffic and Rab1 rescues neuron loss in Parkinson's models. Science. 2006;313(5785):324-8.

145. Hoozemans JJM, van Haastert ES, Eikelenboom P, de Vos RAl, Rozemuller JM, Scheper W. Activation of the unfolded protein response in Parkinson's disease. Biochem Biophys Res Commun. 2007;354(3):707-11.

146. Smith WW, Jiang H, Pei Z, Tanaka Y, Morita H, Sawa A, et al. Endoplasmic reticulum stress and mitochondrial cell death pathways mediate A53T mutant alpha-synuclein-induced toxicity. Hum Mol Genet. 2005;14(24):380111.

147. Imai Y, Soda M, Takahashi R. Parkin suppresses unfolded protein stressinduced cell death through its E3 ubiquitin-protein ligase activity. J Biol Chem. 2000;275(46):35661-4.

148. Bouman L, Schlierf A, Lutz AK, Shan J, Deinlein A, Kast J, et al. Parkin is transcriptionally regulated by ATF4: evidence for an interconnection between mitochondrial stress and ER stress. Cell Death Differ. 2011;18(5): 769-82

149. Duplan E, Giaime E, Viotti J, Sevalle J, Corti O, Brice A, et al. ER-stressassociated functional link between Parkin and DJ-1 via a transcriptional cascade involving the tumor suppressor p53 and the spliced X-box binding protein XBP-1. J Cell Sci. 2013;126(Pt 9):2124-33.

150. Duplan E, Sevalle J, Viotti J, Goiran T, Bauer $C$, Renbaum $P$, et al. Parkin differently regulates presenilin-1 and presenilin-2 functions by direct control of their promoter transcription. J Mol Cell Biol. 2013;5(2):132-42.

151. Yuan Y, Cao P, Smith MA, Kramp K, Huang Y, Hisamoto N, et al. Dysregulated LRRK2 signaling in response to endoplasmic reticulum stress leads to dopaminergic neuron degeneration in C. elegans. PLoS One. 2011; 6(8):e22354

152. Matus S, Valenzuela V, Medinas DB, Hetz C. ER dysfunction and protein folding stress in ALS. Int J Cell Biol. 2013;2013:674751.

153. Zarei S, Carr K, Reiley L, Diaz K, Guerra O, Altamirano PF, et al. A comprehensive review of amyotrophic lateral sclerosis. Surg Neurol Int. 2015;6:171.

154. Deng HX, Hentati A, Tainer JA, lqbal Z, Cayabyab A, Hung WY, et al. Amyotrophic lateral sclerosis and structural defects in $\mathrm{Cu}, \mathrm{Zn}$ superoxide dismutase. Science. 1993;261(5124):1047-51.

155. Taylor JP, Brown RH Jr, Cleveland DW. Decoding ALS: from genes to mechanism. Nature. 2016;539(7628):197-206.

156. Rosen DR, Siddique T, Patterson D, Figlewicz DA, Sapp P, Hentati A, et al. Mutations in $\mathrm{cu} / \mathrm{Zn}$ superoxide dismutase gene are associated with familial amyotrophic lateral sclerosis. Nature. 1993;362(6415):59-62.

157. Rosen DR. Mutations in cu/Zn superoxide dismutase gene are associated with familial amyotrophic lateral sclerosis. Nature. 1993;364(6435):362.

158. Renton AE, Majounie E, Waite A, Simón-Sánchez J, Rollinson S, Gibbs JR, et al. A hexanucleotide repeat expansion in C9ORF72 is the cause of chromosome 9p21-linked ALS-FTD. Neuron. 2011;72(2):257-68.

159. Kwiatkowski TJ, Bosco DA, Leclerc AL, Tamrazian E, Vanderburg CR, Russ C, et al. Mutations in the FUS/TLS gene on chromosome 16 cause familial amyotrophic lateral sclerosis. Science. 2009;323(5918):1205-8.

160. Matus S, Glimcher LH, Hetz C. Protein folding stress in neurodegenerative diseases: a glimpse into the ER. Curr Opin Cell Biol. 2011;23(2):239-52.

161. Ilieva EV, Ayala V, Jové M, Dalfó E, Cacabelos D, Povedano M, et al. Oxidative and endoplasmic reticulum stress interplay in sporadic amyotrophic lateral sclerosis. Brain. 2007;130(Pt 12):3111-23.

162. Atkin JD, Farg MA, Walker AK, McLean C, Tomas D, Horne MK. Endoplasmic reticulum stress and induction of the unfolded protein response in human sporadic amyotrophic lateral sclerosis. Neurobiol Dis. 2008;30(3):400-7.

163. Ito Y, Yamada M, Tanaka H, Aida K, Tsuruma K, Shimazawa M, et al. Involvement of CHOP, an ER-stress apoptotic mediator, in both human sporadic ALS and ALS model mice. Neurobiol Dis. 2009;36(3):470-6.

164. Nishitoh H, Kadowaki H, Nagai A, Maruyama T, Yokota T, Fukutomi $H$, et al. ALS-linked mutant SOD1 induces ER stress- and ASK1-dependent motor neuron death by targeting Derlin-1. Genes Dev. 2008;22(11):1451-64.

165. Wang L, Popko B, Roos RP. The unfolded protein response in familial amyotrophic lateral sclerosis. Hum Mol Genet. 2011;20(5):1008-15. 
166. Matus S, Lopez E, Valenzuela V, Nassif M, Hetz C. Functional contribution of the transcription factor ATF4 to the pathogenesis of amyotrophic lateral sclerosis. PLoS One. 2013;8(7):e66672.

167. Hetz C, Thielen P, Matus S, Nassif M, Court F, Kiffin R, et al. XBP-1 deficiency in the nervous system protects against amyotrophic lateral sclerosis by increasing autophagy. Genes Dev. 2009;23(19):2294-306.

168. Atkin JD, Farg MA, Turner BJ, Tomas D, Lysaght JA, Nunan J, et al. Induction of the unfolded protein response in familial amyotrophic lateral sclerosis and association of protein-disulfide isomerase with superoxide dismutase 1. J Biol Chem. 2006;281(40):30152-65.

169. Walker AK, Farg MA, Bye CR, McLean CA, Horne MK, Atkin JD. Protein disulphide isomerase protects against protein aggregation and is $\mathrm{S}$ nitrosylated in amyotrophic lateral sclerosis. Brain. 2010;133(Pt 1):105-16.

170. Halloran M, Parakh S, Atkin JD. The role of s-nitrosylation and sglutathionylation of protein disulphide isomerase in protein misfolding and neurodegeneration. Int J Cell Biol. 2013;2013:797914.

171. Parakh S, Atkin JD. Protein folding alterations in amyotrophic lateral sclerosis. Brain Res. 2016;1648(Pt B):633-49.

172. Zhang YJ, Jansen-West K, Xu YF, Gendron TF, Bieniek KF, Lin WL, et al. Aggregation-prone c9FTD/ALS poly(GA) RAN-translated proteins cause neurotoxicity by inducing ER stress. Acta Neuropathol. 2014;128(4):505-24.

173. Walker AK, Soo KY, Sundaramoorthy $V$, Parakh S, Ma Y, Farg MA, et al. ALSassociated TDP-43 induces endoplasmic reticulum stress, which drives cytoplasmic TDP-43 accumulation and stress granule formation. PLoS One. 2013;8(11):e81170

174. Farg MA, Sundaramoorthy V, Sultana JM, Yang S, Atkinson RA, Levina V, et al. C9ORF72, implicated in amytrophic lateral sclerosis and frontotemporal dementia, regulates endosomal trafficking. Hum Mol Genet. 2014;23(13):3579-95.

175. Dormann D, Rodde R, Edbauer D, Bentmann E, Fischer I, Hruscha A, et al. ALS-associated fused in sarcoma (FUS) mutations disrupt Transportinmediated nuclear import. EMBO J. 2010;29(16):2841-57.

176. Farg MA, Soo KY, Walker AK, Pham H, Orian J, Horne MK, et al. Mutant FUS induces endoplasmic reticulum stress in amyotrophic lateral sclerosis and interacts with protein disulfide-isomerase. Neurobiol Aging. 2012;33(12):2855-68.

177. Dendrou CA, Fugger L, Friese MA. Immunopathology of multiple sclerosis. Nat Rev Immunol. 2015;15(9):545-58.

178. Ransohoff RM, Kivisakk P, Kidd G. Three or more routes for leukocyte migration into the central nervous system. Nat Rev Immunol. 2003:3(7):569-81.

179. Hoglund RA, Maghazachi AA. Multiple sclerosis and the role of immune cells. World J Exp Med. 2014;4(3):27-37.

180. Goverman J. Autoimmune T cell responses in the central nervous system. Nat Rev Immunol. 2009;9(6):393-407.

181. Libbey JE, McCoy LL, Fujinami RS. Molecular mimicry in multiple sclerosis. Int Rev Neurobiol. 2007;79:127-47.

182. Virtanen JO, Jacobson S. Viruses and multiple sclerosis. CNS Neurol Disord Drug Targets. 2012;11(5):528-44.

183. Cunnea P, Mháille AN, McQuaid S, Farrell M, McMahon J, FitzGerald U. Expression profiles of endoplasmic reticulum stress-related molecules in demyelinating lesions and multiple sclerosis. Mult Scler. 2011;17(7):808-18.

184. Mháille AN, McQuaid S, Windebank A, Cunnea P, McMahon J, Samali A, et al. Increased expression of endoplasmic reticulum stress-related signaling pathway molecules in multiple sclerosis lesions. J Neuropathol Exp Neurol. 2008;67(3):200-11.

185. Werner P, Pitt D, Raine CS. Glutamate excitotoxicity-a mechanism for axonal damage and oligodendrocyte death in multiple sclerosis? J Neural Transm Suppl. 2000;60:375-85

186. Yu Z, Luo H, Fu W, Mattson MP. The endoplasmic reticulum stressresponsive protein GRP78 protects neurons against excitotoxicity and apoptosis: suppression of oxidative stress and stabilization of calcium homeostasis. Exp Neurol. 1999;155(2):302-14.

187. Hussien Y, Podojil JR, Robinson AP, Lee AS, Miller SD, Popko B. ER chaperone BiP/GRP78 is required for Myelinating cell survival and provides protection during experimental autoimmune encephalomyelitis. J Neurosci. 2015:35(48):15921-33.

188. Dimcheff DE, Faasse MA, McAtee FJ, Portis JL. Endoplasmic reticulum (ER) stress induced by a neurovirulent mouse retrovirus is associated with prolonged BiP binding and retention of a viral protein in the ER. J Biol Chem. 2004:279(32):33782-90.

189. Lin W, Harding HP, Ron D, Popko B. Endoplasmic reticulum stress modulates the response of myelinating oligodendrocytes to the immune cytokine interferon-gamma. J Cell Biol. 2005;169(4):603-12.
190. Xu K, Zhu XP. Endoplasmic reticulum stress and prion diseases. Rev Neurosci. 2012;23(1):79-84

191. Torres M, Castillo K, Armisen R, Stutzin A, Soto C, Hetz C. Prion protein misfolding affects calcium homeostasis and sensitizes cells to endoplasmic reticulum stress. PLoS One. 2010;5(12):e15658.

192. Torres M, Encina G, Soto C, Hetz C. Abnormal calcium homeostasis and protein folding stress at the ER: a common factor in familial and infectious prion disorders. Commun Integr Biol. 2011;4(3):258-61.

193. Cai Y, Arikkath J, Yang L, Guo ML, Periyasamy P, Buch S. Interplay of endoplasmic reticulum stress and autophagy in neurodegenerative disorders. Autophagy. 2016;12(2):225-44.

194. Akay C, Lindl KA, Shyam N, Nabet B, Goenaga-Vazquez Y, Ruzbarsky J, et al. Activation status of integrated stress response pathways in neurones and astrocytes of HIV-associated neurocognitive disorders (HAND) cortex. Neuropath Appl Neurobiol. 2012;38(2):175-200.

195. Wei H, Kim S-J, Zhang Z, Tsai P-C, Wisniewski KE, Mukherjee AB. ER and oxidative stresses are common mediators of apoptosis in both neurodegenerative and non-neurodegenerative lysosomal storage disorders and are alleviated by chemical chaperones. Human Mol Gen. 2008;17(4):469-77.

196. Bosch ME, Kielian T. Neuroinflammatory paradigms in lysosomal storage diseases. Front Neurosci. 2015:9:417.

197. Riemer C, Gültner S, Heise I, Holtkamp N, Baier M. Neuroinflammation in prion diseases: concepts and targets for therapeutic intervention. CNS Neurol Disord Drug Targets. 2009;8(5):329-41.

198. Gannon P, Khan MZ, Kolson DL. Current understanding of HIV-associated neurocognitive disorders pathogenesis. Curr Opin Neurol. 2011;24(3):275-83.

199. Martinon F, Glimcher LH. Regulation of innate immunity by signaling pathways emerging from the endoplasmic reticulum. Curr Opin Immunol. 2011;23(1):35-40.

200. Zanetti M, Rodvold JJ, Mahadevan NR. The evolving paradigm of cellnonautonomous UPR-based regulation of immunity by cancer cells. Oncogene. 2016;35(3):269-78.

201. Alliot F, Godin I, Pessac B. Microglia derive from progenitors, originating from the yolk sac, and which proliferate in the brain. Brain Res Dev Brain Res. 1999;117(2):145-52.

202. Kawabori M, Yenari MA. The role of the microglia in acute CNS injury. Metab Brain Dis. 2015;30(2):381-92.

203. Katsumoto A, Lu H, Miranda AS, Ransohoff RM. Ontogeny and functions of central nervous system macrophages. J Immunol. 2014;193(6):2615-21.

204. Miranda-Hernandez S, Baxter AG. Role of toll-like receptors in multiple sclerosis. Am J Clin Exp Immunol. 2013;2(1):75-93.

205. Farina C, Aloisi F, Meinl E. Astrocytes are active players in cerebral innate immunity. Trends Immunol. 2007;28(3):138-45.

206. Bjorkqvist M, Wild EJ, Thiele J, Silvestroni A, Andre R, Lahiri N, et al. A novel pathogenic pathway of immune activation detectable before clinical onset in Huntington's disease. J Exp Med. 2008;205(8):1869-77.

207. Ledo JH, Azevedo EP, Beckman D, Ribeiro FC, Santos LE, Razolli DS, et al. Cross talk between brain innate immunity and serotonin signaling underlies depressive-like behavior induced by Alzheimer's Amyloid-beta Oligomers in mice. J Neurosci. 2016;36(48):12106-16.

208. Paresce DM, Ghosh RN, Maxfield FR. Microglial cells internalize aggregates of the Alzheimer's disease amyloid beta-protein via a scavenger receptor. Neuron. 1996:17(3):553-65.

209. Minagar A, Shapshak P, Fujimura R, Ownby R, Heyes M, Eisdorfer C. The role of macrophage/microglia and astrocytes in the pathogenesis of three neurologic disorders: HIV-associated dementia, Alzheimer disease, and multiple sclerosis. J Neurol Sci. 2002;202(1-2):13-23.

210. Harvey LD, Yin Y, Attarwala IY, Begum G, Deng J, Yan HQ, et al. Administration of DHA reduces endoplasmic reticulum stress-associated inflammation and alters Microglial or macrophage activation in traumatic brain injury. ASN Neuro. 2015;7(6):1-15.

211. Hosoi T, Honda M, Oba T, Ozawa K. ER stress upregulated PGE $/$ IFNYinduced IL-6 expression and down-regulated iNOS expression in glial cells. Sci Rep. 2013;3:3388.

212. Guthrie LN, Abiraman K, Plyler ES, Sprenkle NT, Gibson SA, McFarland BC, et al. Attenuation of PKR-like ER Kinase (PERK) signaling selectively controls endoplasmic reticulum stress-induced inflammation without compromising immunological responses. J Biol Chem. 2016;291(30):15830-40.

213. Halliday M, Radford H, Sekine Y, Moreno J, Verity N, le Quesne J, et al. Partial restoration of protein synthesis rates by the small molecule ISRIB prevents neurodegeneration without pancreatic toxicity. Cell Death Dis. 2015;6:e1672. 
214. Moreno JA, Halliday M, Molloy C, Radford H, Verity N, Axten JM, et al. Oral treatment targeting the unfolded protein response prevents

Neurodegeneration and clinical disease in Prion-infected mice. Sci Transl Med. 2013;5(206):206ra138.

215. Grootjans J, Kaser A, Kaufman RJ, Blumberg RS. The unfolded protein response in immunity and inflammation. Nat Rev Immunol. 2016;16(8): 469-84.

Submit your next manuscript to BioMed Central and we will help you at every step:

- We accept pre-submission inquiries

- Our selector tool helps you to find the most relevant journal

- We provide round the clock customer support

- Convenient online submission

- Thorough peer review

- Inclusion in PubMed and all major indexing services

- Maximum visibility for your research

Submit your manuscript at www.biomedcentral.com/submit 